\title{
Ceria Catalysts at Nanoscale: How Do Crystal Shapes Shape Catalysis?
}

\author{
Alessandro Trovarellia and Jordi Llorca ${ }^{\mathrm{b}}$

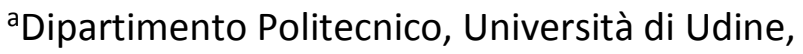 \\ via del Cotonificio 108, 33100 Udine (Italy).trovarelli@uniud.it \\ ${ }^{b}$ Institute of Energy Technologies, Department of Chemical Engineering and Barcelona Research Center in \\ Multiscale Science and Engineering, Universitat Politècnica de Catalunya, EEBE, Eduard Maristany 10-14, \\ 08019 Barcelona (Spain). jordi.llorca@upc.edu
}

\begin{abstract}
Engineering the shape and size of catalyst particles and the interface between different components of heterogeneous catalysts at nanometer level can radically alter their performances. This is particularly true with $\mathrm{CeO}_{2}$-based catalysts, where the precise control of surface atomic arrangements can modify the reactivity of $\mathrm{Ce}^{4+} / \mathrm{Ce}^{3+}$ ions, changing the oxygen release/uptake characteristics of ceria, which, in turn, strongly affects catalytic performance in several reactions like CO, soot and VOC oxidation, WGS, hydrogenation, acid-base reactions and so on. Despite many of these catalysts are polycrystalline with rather ill-defined morphologies, experimental and theoretical studies on well-defined nanocrystals have clearly established that the exposure of specific facets can increase/decrease surface oxygen reactivity and metal-support interaction (for supported metal nanoparticles), consequently affecting catalytic reactions. Here, we want to address the most recent developments in this area, showing that shape (and size) modification, surface/face reconstruction and faceting of ceria at the nanoscale level can offer an important tool to govern activity and stability in several reactions and imagine how this could contribute to future developments.
\end{abstract}

Keywords: $\mathrm{CeO}_{2}$, nanorods, nanocubes, nanocrystals, metal-support interaction, oxygen storage capacity. 


\section{INTRODUCTION}

The engineering at nanometer level of the size, the shape and face of individual particles is of great importance to control the surface chemistry of oxide and metal nanoparticles (NP), which are the key ingredients in catalysis recipes ${ }^{1-4}$. In the last two decades, the nanoscale approach to the understanding of material chemistry and its application in catalysis has experienced an unprecedented growth due to the development of advanced characterization techniques and the successful combination of theory and experiment in the "bottom up" design of heterogeneous catalysts. This has also been driven by the parallel development of surface science approach which allowed a better understanding of model catalytic systems ${ }^{5}$. Ceria $\left(\mathrm{CeO}_{2}\right)$ is a good example where the fundamental studies at nanoscale level offer a precious tool to understand its mechanism of action as catalyst or promoter, and they result crucial for obtaining materials with enhanced properties.

The field of ceria-containing catalysts has experienced an explosive growth in the last 20 years fostered also by the excellent level of fundamental knowledge that has accumulated over the years, and it is documented by the great number of seminal reviews and books on the use of $\mathrm{CeO}_{2}$ as catalyst, catalyst support or even as simple ingredient ${ }^{6-11}$. In addition to its well-known ability to switch Ce oxidation state while maintaining structural integrity, there are a number of important functions that ceria performs in catalytic reactions specifically at nanoscale; ceria is able to profoundly modify the reactivity of supported metal particles ${ }^{12-14}$, and particularly those atoms located at the interface perimeter ${ }^{15-16}$ and also to protect metal particles from sintering at high temperature ${ }^{17}$ or to stabilize noble metals in unique single atom configuration ${ }^{18-19}$. The mechanism of oxygen transfer from ceria to metal is responsible for the enhancement of activity in several noble metal-ceria combinations, and it is strongly dependent on morphology and size of ceria particles ${ }^{12,20}$ as well as on the nature of metal-ceria interface ${ }^{21}$. Ceria NPs are therefore preferred compared to bulk materials due to the wide number of unique features that can be assembled in a single oxide composition.

In combination with theoretical approach it was established and predicted in the early ' 90 that the formation of an oxygen vacancy on ceria is strongly surface sensitive, meaning that the redox reactivity of ceria crystals with different types of exposed facets might follow different ordering ${ }^{22-}$ 23. To bridge the gap between these early theoretical investigations on model systems and studies of real catalysts under operative conditions a great effort was put on the preparation of ceriabased materials containing crystals with uniform and controlled morphologies. Standard 
preparation techniques like precipitation/coprecipitation, do not guarantee a good level of morphological homogeneity; polycrystalline sample of $\mathrm{CeO}_{2}$ with ill-defined morphologies are typically obtained with these methodologies and crystal shape control is virtually impossible. Although templating and structure directing agents can help in obtaining specific morphologies ${ }^{24-}$ 25 , the use of hydrothermal methods with no additives has been widely used in the last years to control the shape and size of ceria particle during synthesis ${ }^{26-28}$. Early applications of hydrothermal methods to prepare $\mathrm{CeO}_{2}$-based materials date back to early ninetees ${ }^{29}$; however it was only ten years later that the shape of ceria crystals obtained by these methods was clearly disclosed using careful HRTEM analysis ${ }^{30}$. By the control of a few critical parameters during reaction $(\mathrm{pH}$, temperature and pressure), it was then possible to prepare and to modify in a predictable way the morphology of ceria crystals to create different nanoshapes like rods ${ }^{31}$, cubes $^{26}$, wires ${ }^{32}$, tubes $^{33}$ and spheres $^{34}$.

These nanocrystals expose different surfaces in addition to the most stable $\{111\}$-type facet, and their use made possible laboratory investigations on the correlation between catalytic properties and specific morphology. In 2005, Li et al. first compared the catalytic properties of ceria nanorods and ceria NPs in $\mathrm{CO}$ oxidation ${ }^{35}$. They found nanorods more active than nanoparticles and attributed this difference to the higher reactivity of $\{100\} /\{110\}$ exposed planes. Similarly, OSC properties of ceria nanocubes and nanorods were also investigated and a clear relationship between oxygen uptake/release and surface morphology was found in agreement with earlier predictions $^{26}$. At the same time it was also found that CO oxidation on polycrystalline ceria sample is positively influenced by increasing the amount of $\{100\}$ exposed surfaces ${ }^{36}$. The higher reactivity of CO toward $\{110\} /\{100\}$ facets was also verified by DFT calculations by comparison of adsorption and oxidation of $\mathrm{CO}$ over these surfaces with participation of oxygen vacancies ${ }^{37-38}$. Following these studies, a great number of ceria nanoshapes have then been prepared, characterized and used as catalysts or supports in several reactions. Most of the early work in the field (2005-2012) has been nicely reviewed by several groups. In particular, Zhang et al. ${ }^{39}$ and Sun et al..$^{40}$ paid particular attention on the preparative chemistry of ceria nanoparticles, while Huang and Gao ${ }^{41}$ described mainly the characterization and catalytic behavior with a focus on the correlation between surface properties and reactivity. The spectroscopic characterization of adsorbates in ceria-based nanomaterials was addressed by Sheng et al. ${ }^{42}$ while a specific scrutiny of Au-based catalysts over nanoshaped ceria was given by Ta et al. ${ }^{43}$ Recently Wu et al. ${ }^{44}$ described more systematically the synthesis of ceria-based nanocatalysts with several morphologies and their 
applications in the field of energy and environment. The effect of catalyst morphology with specific attention to the combination of metal/ceria into high order arrangements was also addressed by the group of Fornasiero in recent reviews and connected to the general aspects of ceria catalysis $^{9,45}$. Here, we want to address the most recent developments in this area focusing precisely on the correlation between surface properties, crystal size and morphology of the three most common ceria shapes like nanopolyhedra, nanorods and nanocubes in the absence and in the presence of an active metal phase. We will show that shape and size modification, surface/face reconstruction and faceting of ceria crystallites at the nanoscale, when properly controlled, can offer an important tool to govern activity, stability and selectivity in several important reactions and imagine how this could contribute to future developments.

\section{SURFACE CHEMISTRY OF CERIA}

2.1 Shape dependent behavior. The three thermodynamically most stable surfaces of ceria are the $\{111\},\{110\}$ and $\{100\}^{23,46-47}$. The $\{211\}$ surface has also been reported to be quite stable, but it easily reconstructs into a stepped $\{111\}$ surface. Other surfaces like the $\{210\}$ and $\{310\}$ are less stable and suffer severe reconstruction/faceting making them quite unlikely in real systems ${ }^{23}$. Therefore, many studies have been focused on three more stable low index surfaces. Table 1 summarizes a few important characteristics of these surfaces ${ }^{48}$; the $\{111\}$ is the most stable as can be seen from the lower surface energy values, followed by the $\{110\}$ and the least stable $\{100\}$. For all the three surfaces, coordination number is lower than that found in bulk $\mathrm{CeO}_{2}$ crystals ( 4 for oxygens and 8 for cerium atoms), with the smaller values indicating less stable surfaces. The $\{111\}$ is an oxygen terminating surface with a repeating $\mathrm{O}-\mathrm{Ce}-\mathrm{O}-\mathrm{O}-\mathrm{Ce}-\mathrm{O}$ layer structure (Figure 1) with no net dipole moment, due to the three layers $\mathrm{O}-\mathrm{Ce}-\mathrm{O}$ which maintains charge neutrality. Both $\mathrm{O}$ and Ce have a single coordinative unsaturated site indicating that only one adsorbate can link to these sites $^{49}$. The $\{110\}$ surface exposes both $\mathrm{O}$ and $\mathrm{Ce}$ ions and each surface layer has zero charge due to a stoichiometric balance of oxygen and cerium in each plane. Modelling studies suggests that this surface should undergo substantial relaxation with the oxygen atoms moving outward and the cerium ions relaxing inward compared to the flat layer ${ }^{50}$. Oxygen and cerium carry respectively one and two coordinative unsaturated sites. The $\{100\}$ surface is the least stable and consists of a O-Ce-O-Ce repeating unit which generate a net dipole moment perpendicular to the surface; calculations on this surface are therefore carried out by moving half of the oxygens from the top to the bottom surface to eliminate the dipole. In contrast to $\{111\}$, atomistic surface dynamics of 
the $\{100\}$-type facet reveals that this is dominated by movements of cerium atoms in the first two layers $^{51}$. Structural characterization of this surface is not definitive and location of oxygen on the relaxed surface is still a matter of debate ${ }^{49}$ being strongly dependent on sample history (synthesis and thermal treatments) and influenced by the level of surface disorder ${ }^{52}$. Surface reconstruction, surface roughening and creation of defects are the likely mechanisms suggested to lower the energy in this type of polar surfaces ${ }^{53}$. In this facet both $\mathrm{O}$ and Ce have two coordinative unsaturated sites.

One of the more important features of ceria surfaces is that they show different reduction characteristics; these differences were first recognized by theoretical simulation studies ${ }^{22}$ that are at the core of the understanding of the fascinating catalytic properties of ceria nanoparticles. During reduction, electrons from the oxygen atom are transferred to two adjacent cerium atoms that are reduced from $\mathrm{Ce}^{4+}$ to $\mathrm{Ce}^{3+}$ and an oxygen vacancy is formed according to the following process:

$$
\mathrm{O}_{\mathrm{O}}^{\mathrm{x}}+2 \mathrm{Ce}_{\mathrm{Ce}}^{\mathrm{x}} \rightarrow \mathrm{V}_{\mathrm{O}}^{\circ \circ}+2 \mathrm{Ce}_{\mathrm{Ce}}^{\prime}+1 / 2 \mathrm{O}_{2}
$$

Vacancies are mobile reactive sites which can act as centers for oxygen activation in oxidation reactions and that are the key ingredient in the oxygen storage process. The $\{111\}$ surface is the most compact and less prone to accommodate a vacancy defect as can be seen from its vacancy formation energy which is the highest among the three low index surfaces ${ }^{22-23,54}$. Table 1 shows the energies calculated according to DFT calculations with inclusion of on-site electronic interactions ${ }^{54}$. Other methods can give different numerical results, although the order of reactivity for the vacancy defect formation (i.e. $\{110\}>\{100\}>\{111\}$ ) remains the same $22-23,48,55-56$. This, in principle, will imply that the redox activity of ceria can be altered by preparing crystals with different exposed faces (and thus different shapes); catalytic reactions that are driven by the redox behavior will be therefore affected by different surface exposure. The strong predictive nature of this statement set the basis for several experimental studies on ceria nanocrystals that were successively developed, where a clear correlation between crystal shape and catalytic activity/selectivity was established.

2.2 Size dependent behavior. The other key parameter that modifies the surface chemistry of ceria at nanoscale level is the particle size. It was first experimentally observed by Tsunekawa et al. ${ }^{57-58}$ that monodisperse cerium oxide NPs with size ranging from ca. 2 to $8 \mathrm{~nm}$ show a 
remarkable increase in their lattice constant compared to bulk $\mathrm{CeO}_{2}$, as measured by electron diffraction patterns. This lattice relaxation was induced by the size of the particles, with smaller particles showing the larger increase and it was associated to the reduction of the valence of $\mathrm{Ce}$ with decreasing particle size. This charge reduction from +4 to +3 of cerium ions results in a decrease of electrostatic forces that ultimately induce an increase of the lattice constant. A correlation between oxygen vacancy concentration and ceria crystal size was also measured by Zhou and Huebner ${ }^{59}$ who found a large increase in oxygen vacancy concentration with $\mathrm{CeO}_{2}$ crystal size $<10 \mathrm{~nm}$. The large surface to volume ratio of $\mathrm{CeO}_{2} \mathrm{NP}$ exposing several surface atoms with reduced coordination can ultimately lead to a formulation of $\mathrm{CeO}_{2-\mathrm{x}}$ in a fluorite lattice as the structure for ceria nanoparticles ${ }^{60-61}$.

Along these lines, more recent modelling studies have investigated the easy of vacancy formation on ceria nanoparticles with variable size. Neyman and coworkers, in a series of elegant studies, investigated the oxygen vacancy formation energies in ceria nanoparticles $\left(\mathrm{CeO}_{2}\right)_{\mathrm{n}}$ as a function of size, by varying $\mathrm{n}$ from 20 to $140^{62-64}$. The energy for vacancy formation is strongly dependent on the oxygen position in the ceria nanocrystal; Figure 2 shows the potential location of a vacancy in a stoichiometric $\mathrm{Ce}_{40} \mathrm{O}_{80}$ nanoparticle with the calculated vacancy formation energy. The data shows that the most stable vacancy site is obtained by removing an open 2 coordinate oxygen at the intersection between $\{100\}$ and $\{111\}$-type facets; with a great variability in the vacancy formation energy between the least and the most stable vacancy (ca. $1.8 \mathrm{eV}$ ). This means that there is a great variability in the energy needed to abstract oxygen, but most importantly, they found that removal of oxygen is strongly facilitated for particle dimensions in the range of 2-4 $\mathrm{nm}$ compared to extended surfaces, with the vacancy formation energy that reaches a minimum with $\mathrm{Ce}_{80} \mathrm{O}_{160}$ (Figure 3). Thus, moving from a regular $\mathrm{CeO}_{2}\{111\}$ surface and reducing the dimension of the particle, the oxygen vacancy generation in selected positions is favored, which is in agreement with the increased reducibility observed in monodisperse ceria NPs. This can also help explaining the unique size-dependent properties observed in ceria at nanoscale like the boosting of the oxygen transfer to $\mathrm{Pt}$ metal ${ }^{20}$ and the increased oxidation activity in supported catalysts ${ }^{12}$. Other explanations for this size induced lattice relaxation invoke the increased surface energy strain due to the high surface to volume ratio in small size $\mathrm{CeO}_{2} \mathrm{NPs}$. These studies found no evidence for increased $\mathrm{Ce}^{3+}$ and oxygen vacancy concentration; interestingly, they detected formation of surface superoxide species through adsorption of molecular oxygen ${ }^{65}$. In this case, $\mathrm{Ce}^{3+}$ sites which are present in under stoichiometric $\mathrm{CeO}_{2} \mathrm{NPs}$ and are not necessarily associated to an oxygen 
vacancy ${ }^{66}$ can act as a center for adsorption of $\mathrm{O}_{2}$ to give $\mathrm{O}_{2}{ }^{-}$, increasing the formation of active oxygen species and thus boosting oxygen storage activity ${ }^{67-69}$ and low temperature oxidation activity $^{70}$. We will return to this debated aspect in a next section.

\section{NANOSHAPED CERIA PARTICLES}

Crystal morphology is the result of a delicate balance between kinetic and thermodynamic processes that establish during the particle growing process. Under thermodynamic control the most stable surfaces will be formed, which often does not bring to NPs with a specific shape. Thus, the synthesis of crystal face with higher surface energy occurs through the kinetic control of nucleation and growth rate of the crystal in the different directions ${ }^{71}$. These are controlled by several parameters such us pressure, temperature, $\mathrm{pH}$, solvent, concentration and characteristics of precursors and additives. Ceria nanoparticles having a fcc structure commonly crystallizes in polyhedral shapes enclosed mainly within low energy surfaces of the $\{111\}$ family followed by $\{110\}$ and $\{100\}$. This produces in $\mathrm{CeO}_{2}$ the typical octahedral or truncated octahedral geometries with $\{111\}$ and $\{100\}$ as major facets (Figure 4) $30,72-74$. The growth rate of the crystal in the different directions can be changed by modifying its surface anisotropy using additives or playing with experimental conditions. This results in the formation of structures having similar dimensions in all directions (zero dimensional, OD structures like nanospheres, nanocubes, nanopolyhedra), with one elongated direction (1D nanowires, nanorods, nanobelts), and with one flattened direction (2D nanoplates, nanosheets) or even hollow and tubular structures ${ }^{1,27,75}$.

The use of organic/inorganic additives as capping agents is frequently employed to selectively block the growing of the crystal in one specific direction and thus favor the development of specific surfaces ${ }^{76-78}$. As an example, Figure 5 shows the growing of a ceria nanocrystal in the presence of decanoic acid, which preferentially interacts with the $\{100\}$ family planes, thus reducing the crystal growth in the [100] direction and increasing the growth rate in the [111] direction. This increases the amount of $\{100\}$ exposed surfaces leading to formation of a cubic-like morphology. By further increasing the amount of capping agent, blocking of both surface growing directions occurs, leading to truncated octahedral of smaller dimensions ${ }^{77}$. The use of templates is also quite common to synthesize hollow materials with various morphologies like nanospheres and nanotubes ${ }^{79-80}$. In this case the growth of the crystal is oriented or forced by the template which is added to promote the assembly of nanoparticles into different morphologies ${ }^{39}$. Overall, high surface area and homogeneous particle sizes can be obtained with these methods, which 
conversely suffer from the necessity to remove the additive which might be a drawback when clean $\mathrm{CeO}_{2}$ surfaces with maximum reactive sites are required ${ }^{39}$. As such, template/surfactant free routes have been extensively investigated to obtain $\mathrm{CeO}_{2}$ nanomaterials with minimum surface impurities. The hydrothermal/solvothermal process is one of the more powerful and simple methodologies to prepare ceria nanocrystals with shape control and without the necessity of adding templating or other structure directing agents ${ }^{27,81}$. The method can be employed also to prepare hollow 1D nanostructure like nanotubes ${ }^{33,82-83}$. Typically, with this approach, a cerium salt, either $\mathrm{Ce}\left(\mathrm{NO}_{3}\right)_{3} \cdot \mathrm{nH}_{2} \mathrm{O}^{26}$ or $\mathrm{CeCl}_{3} \cdot \mathrm{nH}_{2} \mathrm{O}^{31}$ (but other precursors have also been used $\left.{ }^{84}\right)$ is dissolved in water in the presence of a base $(\mathrm{NaOH}, \mathrm{KOH}$, $\mathrm{NH}_{3}$ ) and the resulting suspension is transferred into a Teflon-lined autoclave and held at temperature in the range $373-473 \mathrm{~K}$ for $20-50$ hours. Depending on a delicate balance between Cerium concentration, counterion, $\mathrm{pH}$, temperature and time, different particle shapes and sizes can be obtained. In the absence of templating agents the driving force for building different crystal shapes is the structural anisotropy of the inorganic compounds and the chemical potential in solutions ${ }^{26,85}$. The structural isotropic nature makes difficult for ceria to grow anisotropically producing shapes different from polyhedra. However, the presence of anisotropic intermediates during the hydrothermal process ${ }^{26}$ and/or the functioning of counterions of precursor as capping agents $^{86}$ can facilitate different growing direction of the crystals with formation of nanoshapes. In one of the standard receipts for preparing nanocubes and nanorods, Mai et al. ${ }^{26}$ found that the driving force for developing the rod structure was the large structural anisotropy of $\mathrm{Ce}(\mathrm{OH})_{3}$ nuclei, formed by precipitation after addition of concentrated $\mathrm{NaOH}(6-9 \mathrm{M})$ to a $\mathrm{Ce}\left(\mathrm{NO}_{3}\right)_{3} \cdot 6 \mathrm{H}_{2} \mathrm{O}$ solution. Due to this structural anisotropy, rod shape $\mathrm{Ce}(\mathrm{OH})_{3}$ nanocrystals were readily formed during hydrothermal synthesis at high $\mathrm{pH}$ and were then converted to $\mathrm{CeO}_{2}$ upon drying without losing the shape. The high $\mathrm{pH}$ was necessary to induce a high rate of dissolution and precipitation with formation of highly crystalline samples. Increasing the temperature, a higher selectivity toward nanocubes was obtained ${ }^{26,32}$. In addition to $\mathrm{pH}$ and temperature the nature of the precursor/counterion can also control the final shape of nanocrystals ${ }^{86-87}$; chloride and nitrate ions can selectively interact with the $\{111\}$ and $\{100\}$ facet of the growing $\mathrm{CeO}_{2}$ crystal, respectively, changing the surface free energies and thus controlling the growth rate of different facets. For these reasons the presence of $\mathrm{Cl}^{-}$favors formation of elongated 1D structures like nanowires and nanorods while $\mathrm{NO}_{3}{ }^{-}$favors nanoparticles or nanocubes. The overall behavior can be outlined as in Figure 6 where in part A the fate of 
$\mathrm{Ce}(\mathrm{OH})_{3}$ nuclei to give nanoparticles, nanorods or nanocubes is shown as a function of counterion, $\mathrm{pH}$ and temperature ${ }^{86}$, while part $\mathrm{B}$ shows the morphological shape diagram of $\mathrm{CeO}_{2}$ after hydrothermal synthesis, adapted from the original source ${ }^{88}$ to include also results from other investigations. Modification of the standard hydrothermal methods/receipts have also been reported, including the change of the base and the precursors to obtain modified rod structure, nanowires and octahedral particles ${ }^{81,89-90}$. Chen et al. ${ }^{91}$, using peroxyacetic acid as oxidant and in the absence of any template, were also able to promote the formation of single crystalline hollow nanocubes with a dimension of ca. $120 \mathrm{~nm}$ and a shell thickness of $30 \mathrm{~nm}$. This shows the great versatility and simplicity of the methodology which can be used to prepare a great number of different morphology by carefully playing with selected parameters.

3.1 Nanocubes. Among the great mosaic of ceria nanoshapes, cubic and rod-like morphologies are the most widely investigated and characterized for catalytic applications ${ }^{92}$. This is due to the relatively simple preparation procedure coupled with their shape stability that allows characterization under various conditions. The structure of a $\mathrm{CeO}_{2}$ nanocube is a particle enclosed by six $\{100\}$ faces with size ranging from a few nanometers ${ }^{93}$ to more than $100 \mathrm{~nm}^{76}$. The ideal cubic structure is seldom shown in literature and more frequently nanocubes show round corners and edges which expose $\{111\}$ and $\{110\}$ surfaces, respectively (Figure 7$)^{74}$. Detailed HRTEM measurements at quasi atomic resolution revealed that all the surfaces show large deviation from their ideal behavior with strong ionic relaxation ${ }^{94-95}$. The $\{100\}$ surface can show multiple surface terminations (either $\mathrm{Ce}, \mathrm{O}$, or $\mathrm{Ce}-\mathrm{O}$ ) and a high degree of reduction in the outermost layer which extend up to ca. $1 \mathrm{~nm}$ deep. The portion of $\{111\}$ and $\{110\}$ surfaces compared to $\{100\}$ in a nanocube can be modified by selectively blocking the growth rate along the $\{111\}$ and $\{100\}$ direction using capping agents during synthesis ${ }^{77-78}$ which results in the formation of truncated octahedral geometries. Thermal treatments can also modify the shape of nanocubes that reveal morphological changes with formation of capping edges and round corners ${ }^{96}$ and $\{111\}$ faceting of the $\{100\}$ flat surface ${ }^{97}$ above $773 \mathrm{~K}$ and $600 \mathrm{~K}$, respectively. Similar changes can be originated by electron beam irradiation ${ }^{95}$. Increasing the temperature up to $1173 \mathrm{~K}$ results in the formation of rounded particles, which originates from a modification of a cubic shape to a cube with cut corners as a first step followed by formation of a cube with truncated corners and edges and finally an irregular truncated cuboctahedron, which would resemble a round particle in HRTEM images $^{72}$. Similarly, starting from polycrystalline ceria samples mainly constituted by octahedral particles, high temperature treatment results in particle truncation with overall sintering and 
exposure of $\{100\} /\{110\}$ surfaces $^{36}$, a process which is analogous to that observed on thin $\mathrm{CeO}_{2}$ films, where annealing in the presence of oxygen induces truncation of $\{111\}$ faces with formation of $\{100\}$ surfaces $^{98-99}$. This is summarized in Figure 8 that shows the transformation of nanocubes into round shape particles with edge and corner cut (Figure 8A) and the truncation of octahedral nanoparticles present in polycrystalline ceria (Figure 8B). In both examples, independently from the shape and the preparation method of the starting material, particles with a truncated octahedral geometry are formed after thermal treatment of nanoparticles and nanocubes. Thus, regardless of the initial morphology, the formation of similar crystal shapes after treatment suggests the existence of a geometrical relationship between the different ceria particles, which have important implication also in the reactivity of crystals ${ }^{96}$. This is also supported by a comparison of geometrical shapes observed with high temperature simulated amorphisation and recrystallization of ceria nanocubes and octahedral nanoparticles ${ }^{100}$ which is represented in Figure $8 \mathrm{C}$ showing that the final model generated in this way (i.e. a truncated octahedra) is independent on the starting configuration.

3.2 Nanorods. A more complicated situation exists with rod-shape morphologies due to the higher reactivity of $\mathrm{Ce}(\mathrm{OH})_{3}$ precursor and the strong influence of reaction conditions on the final morphology. This can lead to different crystal growth direction and exposed planes, as illustrated in Figure 9. Typically, nanorods grow along the [110] direction with $\{100\}$ and $\{110\}$ plane exposure 26,35 , although rods growing through the $[211]^{28,90,101},[111]^{102}$, and $[100]^{76}$ directions with exposed $\{111\}$ and $\{110\}$ faces have also been reported. Symmetry along the cross section can be either hexagonal, pentagonal or rectangular and size measurements indicate strong variability in the aspect ratio, with length $(30-200 \mathrm{~nm})$ and diameter $(5-40 \mathrm{~nm})$ largely influenced by the preparation conditions ${ }^{28,81,90}$; also surface area is generally larger than that observed in nanocubes ${ }^{26,103-104}$. The correlation between preparation methods and precise morphologies has not yet fully understood though it is established that cerium precursors and drying/calcination steps strongly influence the final characteristics of nanorods. Liu et al. found that rods are mostly enclosed either by $\{110\}$ and $\{100\}$ or by $\{111\}$ and $\{100\}$ faces using $\mathrm{Ce}\left(\mathrm{NO}_{3}\right)_{3}$ or $\mathrm{CeCl}_{3}$, respectively ${ }^{105}$. The use of $\mathrm{Ce}\left(\mathrm{NO}_{3}\right)_{3}$ generally results in nanorods exposing the $\{110\}$ and $\{100\}$ faces in agreement with the original preparation method ${ }^{26,35}$, although recently Agarwal et al. ${ }^{106}$, using a similar receipt, found that the only prominent well defined visible facet was the $\{111\}$ surface with all the other being irregular and not well defined. Similarly, the use of $\mathrm{CeCl}_{3}$ has also been associated to nanorods exposing prevalently the $\{111\}$ surface ${ }^{31,90}$. 
One possible explanation for these discrepancies is the calcination temperature of the nanorods. The group of Shen have shown that the prevalently exposed planes changed from $\{110\}$ and $\{100\}$ to $\{111\}$ by thermally treating rods from $673 \mathrm{~K}$ to $973 \mathrm{~K}^{107-108}$; more recently, other groups found that thermal treatment at 873 and $973 \mathrm{~K}$ favors formation of $\{111\}$ exposed planes ${ }^{101,109}$. This is in agreement with the latest findings of Yang et al. ${ }^{110}$ who studied the effect of thermal annealing of ceria nanorods by combined CO adsorption IRRAS and HRTEM using ceria single crystals with $\{111\}$ and $\{110\}$ surfaces. They found that the $\{110\}$ surface of nanorods reconstructs exposing large fractions of $\{111\}$ nanofacets on the $\{110\}$ planes, which can explain why these particles can show either the $\{100\}$ or the $\{110\}$ and $\{111\}$ terminations. Figure 10 shows the $\{111\}$ facets formed on the $\{110\}$ planes and the $\mathrm{CO}$ adsorption characteristics on these facets characterized by peaks at 2154 and $2170 \mathrm{~cm}^{-1}$ respectively. A detailed 3D investigation of ceria nanorods has been conducted by Florea et al. by using electron tomography combined with HRTEM analysis ${ }^{74}$. The study highlights the morphological complexity of rod nanoparticles that show large inhomogeneity in their thickness due to irregular surface topography with a high density of crystallographic defects (which made difficult to assign precise crystallographic planes on the surface) and inhomogeneous internal structure, which is characterized by the presence of internal porosity, a

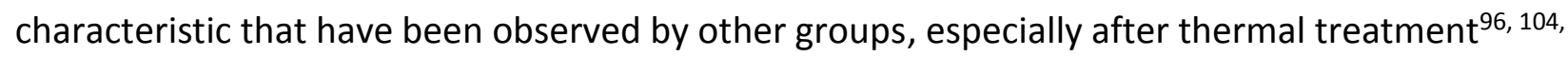
${ }^{111}$. Based on HRTEM and Fourier pattern analysis they adopted a structural model suggested previously by Bugayeva ${ }^{112}$, where the nanorod particle is composed by several coexisting single crystal subunits of complex geometry that grow along the [110] direction.

It can be clearly seen from the above description that these ceria nanoparticles exhibit a rather complex morphology and surface structure with the presence of extensive faceting, various types of defects and an increased amount of highly reactive surfaces which could be responsible for the higher activity generally observed with rod-shaped ceria. Conversely, the diversity of surface characteristics of rod-shaped particles makes their characterization and the unambiguous correlation between catalytic behavior and surface properties at nanoscale a challenging task.

\section{SHAPE DEPENDENT REACTIVITY AND CATALYSIS OF CERIA NANOPARTICLES}

4.1 Oxygen Storage Capacity. The fortune of ceria in catalysis lies in its Oxygen Storage Capacity (OSC) that is the ability $\mathrm{CeO}_{2}$ has to accommodate a large number of oxygen vacancies under slightly reducing atmosphere to give understoichiometric $\mathrm{CeO}_{2-x}$, which can be oxidized back to $\mathrm{CeO}_{2}$ in an oxygen containing atmosphere. This occurs without structural modification of the 
fluorite ceria lattice. Thus, to improve activity of ceria-based catalysts, people have been seeking to maximize the formation of oxygen vacancies, which requires a reducing atmosphere and high temperatures. The group of Yan, investigating the preparation of nanostructured ceria, first observed that nanocubes and nanorods had a higher capacity to store and release oxygen at high temperature compared to octahedral ceria nanoparticles ${ }^{26}$. The increased OSC was associated to the exposure of the more reducible $\{100\}$ and $\{110\}$ planes in nanoshaped ceria and followed the order of nanocubes $>$ nanorods $>>$ nanopolyhedra. The values are reported in Table 2; they are compared with the maximum theoretical surface area-normalized OSC calculated on the three more stable surfaces, and indicate that OSC is not limited to the surface but it takes place also in the bulk.

Other nanoshapes, like 2D ceria nanoplates, with an extended surface to volume ratio, show an even higher surface OSC $\left(7.5 \mu\right.$ moles $\left.\mathrm{O}_{2} \mathrm{~m}^{-2}\right)$ revealing the participation of bulk oxygen in the reduction already at $573 \mathrm{~K}^{113}$. The preparation of nanorods with a high degree of porosity and large surface area resulted in much higher OSC at $673 \mathrm{~K}\left(>900 \mu\right.$ moles $\left.\mathrm{O}_{2} / \mathrm{g}\right)$ attributed to the higher number of oxygen vacancies in porous samples ${ }^{114}$. This was claimed to be the highest OSC value reported for ceria nanostructures, although a direct comparison to rank the properties of materials in terms of OSC is questionable, due to the different methodologies and especially temperatures employed to measure oxygen release. Reduction of ceria followed by temperature programmed reduction in hydrogen $\left(\mathrm{H}_{2}\right.$-TPR) also indicates a superior behavior of nanoshapes compared to ceria NPs; this is evidenced by the anticipation of the onset of surface $\mathrm{Ce}^{4+}$ reduction and by the increase of reduction degree at low temperature that can be associated to the easier oxygen removal from exposed $\{100\}$ and $\{110\}$ surfaces and to the higher density of surface defects present in nanoshapes ${ }^{96,104,115-116}$. Differences in surface area of the starting materials can also influence the overall $\mathrm{H}_{2}$-TPR profiles changing the order of reactivity between nanocubes and nanorods ${ }^{107,117-118}$. Quantitative TPR measurements also estimate a higher degree of overall $\mathrm{CeO}_{2}$ reduction at high temperature in nanoshapes ${ }^{96}$, which again indicates the participation of bulk oxygen in the reduction process.

While it is clearly established that OSC at intermediate/high temperatures (>573-673 K) is dominated by the removal and uptake of oxygen through formation and annihilation of oxygen vacancies, the high OSC activity observed at $373-473 \mathrm{~K}$ in nanorods ${ }^{119}$ and nanocubes ${ }^{120}$ open up interesting implications for low temperature activation of ceria oxygen. Xu et al. ${ }^{65}$ first observed an enhancement of the OSC capacity for small size ceria particles which was related to the 
presence of superoxide ions on the ceria surfaces detected by EPR spectroscopy, and this effect was not related to an increase of oxygen vacancies. Formation of superoxides $\left(\mathrm{O}_{2}^{-}\right)$cannot be simply explained by the interaction of oxygen with a surface vacancy ceria site (that would give peroxide, $\mathrm{O}_{2}^{2-}$ ion ${ }^{121}$ ), but it implies interaction of $\mathrm{O}_{2}$ with surface $\mathrm{Ce}^{3+}$, located apart from an oxygen vacancy, that acts as a one electron donor center to give $\mathrm{Ce}^{4+}-\mathrm{O}_{2}^{-}$complexes ${ }^{122}$. In the presence of oxygen vacancies, the migration barrier from $\mathrm{O}_{2}^{-}$to $\mathrm{O}_{2}^{2-}$ is very low $(0.35 \mathrm{eV}$ for a $\{111\}$ surface) and superoxides can easily transform into peroxides while increasing temperature ${ }^{123}$. However, they have a very high oxidizing power, as they can oxidize CO without activation barrier by forming $\mathrm{CO}_{2}$ and recovering full stoichiometric ceria. After that, a new vacancy must be formed to continue the oxidation process (see Scheme 1a). Therefore, the higher reactivity of ceria nanoparticles can be connected to the easier generation of oxygen vacancies that helps to the formation of transient and active superoxides species.

In the absence of oxygen vacancies the formation of superoxides is likely favored upon direct interaction between oxygen and low-coordinated $\mathrm{Ce}^{3+}$ ions located in edges, steps, corners or dislocations ${ }^{122}$. Such configuration can be found in small understoichiometric ceria nanoparticles (similar to the one studied bu Xu et al. ${ }^{65}$ ), where gas phase oxygen can adsorb for every $\mathrm{Ce}^{3+}$ ion located in corners and ridges forming oxygen charged particles, known as supercharged ceria nanoparticles. These were first suggested on the basis of DFT modelling ${ }^{69}$ and later observed experimentally ${ }^{124}$ in small ceria nanoparticles showing extremely high OSC. Therefore, at low temperature and with highly defective small ceria nanoparticles, oxygen storage has also been related to adsorption and desorption of $\mathrm{O}_{2}$ as superoxide on defective $\mathrm{Ce}^{3+}$ not in proximity to an oxygen vacancy. It is not clear in the above studies if OSC is simply considered as storage of oxygen with no redox implications, or if it is associated to the ability of ceria to oxidize hydrogen or carbon monoxide in a cyclic way, being alternately reduced and oxidized. OSC redox mechanism without formation of oxygen vacancy (and in the absence of supported metal atoms) has not been reported so far, although it was envisioned by Huang and Beck ${ }^{68}$ as a conclusion of their study, and associated to the rich active oxygen chemistry on small size ceria NPs. One such possibility is tentatively depicted in Scheme $1 \mathrm{~b}$ and it involves the transformation of superoxides to peroxides and the cyclic alternation between $\mathrm{Ce}^{3+}$ and $\mathrm{Ce}^{4+}$ without generation of vacancies. However, the feasibility of such cycles needs to be more explicitly addressed if the OSC concept put forward for small supercharged size ceria NPs, in the absence of supported metal, is to be used for developing more active catalysts. 
The formation of superoxide ions has been observed spectroscopically either in nanorods ${ }^{103}$, associated to the high level of defect of their surfaces, and in small nanocubes ${ }^{67}$. In this last case, a mixture of different active molecular adsorbed species $\left(\mathrm{O}_{2}^{-}, \mathrm{O}_{2}^{2-}, \mathrm{O}_{3}, \mathrm{O}_{3}^{-}\right)$were detected on small nanocubes and octahedral nanoparticles with a concentration and distribution which was sizeand shape-dependent, indicating higher adsorption intensities over nanocubes compared to nanooctahedrons, in agreement with their superior oxygen storage capacity. Ongoing DFT studies highlights the formation of active oxygen $\mathrm{O}_{2}^{2-}$ species on step edge-type defects over the $\{111\}$ ceria surface ${ }^{125}$, which demonstrate that not only small size ceria particles but also defects on flat surfaces can generate highly active oxygen species. Therefore, highly defective and faceted surfaces can be a fertile environment for generation of active oxygen species that might explain why nanorods and nanocubes show a superior OSC behavior than nanopolyhedra. The present findings also highlight that the fabrication of active ceria-based redox catalysts need to rely upon the presence of defective surface sites (either $\mathrm{Ce}^{3+}$ or $\mathrm{Ce}^{3+}$ ions associated to a vacancy) that can act as centers to maximize active oxygen adsorption/release under operative conditions. The way this will proceed, especially at low temperatures, is not yet completely known; the shape and the size of ceria crystallites and their surface morphology will certainly make the difference in this regard.

4.2 Catalytic Behavior. Oxidation reaction: The redox and oxygen storage behavior of ceria is closely tied with its catalytic oxidation properties and CO oxidation has been often used as a model reaction to probe the redox properties of $\mathrm{CeO}_{2}$. It is believed to proceed through the Marsvan Krevelen mechanism ${ }^{6}$, where $\mathrm{CO}$ first reacts with surface ceria oxygen giving $\mathrm{CO}_{2}$ (or adsorbed carbonates that subsequently form $\mathrm{CO}_{2}$ ) and leaving an oxygen vacancy which is then filled with gas phase oxygen. A higher reactivity of the $\{110\}$ and $\{100\}$ ceria surfaces toward carbon monoxide oxidation was predicted by computer simulation techniques several years ago ${ }^{22-23}$. In the study of Sayle et al. ${ }^{22}$, it was anticipated that "any processing conditions which favor the formation of these surfaces will result in enhanced activity toward oxidation". Before the introduction of shape selective synthesis there were occasional examples where modification of ceria surfaces allowed to experimentally verify these theoretical findings. In one case, the interaction of $\mathrm{CuO}$ with ceria thin films exposing $\{100\}$ faces resulted in more active $\mathrm{CO}$ oxidation catalysts compared to $\mathrm{CuO}$ in contact with $\{111\} \mathrm{CeO}_{2}$ surfaces and this was attributed to the greater ability of ceria $\{100\}$ to assist copper oxide in changing valence and supplying oxygen ${ }^{98}$. In this case, exposure of $\{100\}$ faces was promoted by thermal annealing of ceria films. Similarly, we 
have shown that polycrystalline cerium dioxide NPs with no preferential face exposure increase the proportion of $\{100\}$ surface exposure upon calcination ${ }^{36}$. Although the process brings to an overall decrease of exposed surface area, the specific CO oxidation activity was strongly increased. CO oxidation over nanoshaped ceria particles was investigated by Zhou et al. ${ }^{35}$ in a study where they compared the light-off performances of nanorods and irregular nanoparticles of similar surface area; the higher activity of the former was attributed to the combination of exposed planes with a higher proportion of $\{100\}$ and $\{110\}$ surfaces. This was the first study where the reactivity of nanoshaped particles (NSP) were examined in CO oxidation and it paved the way for several investigations were the correlation between ceria shapes and CO oxidation was clearly established $^{81,84,107,126-133}$. The light-off activity generally follows the order nanorods $>$ nanocubes> nanoparticles and also the turnover frequency of CO oxidation is higher on $\{110\}$ followed by $\{100\}$ and $\{111\}$ surfaces $^{126}$, which is the reverse order of oxygen vacancy formation energy ${ }^{54}$. Figure 11 shows the light-off performances of the three ceria nanoshapes compared with the evolution of $\mathrm{CO}_{2}$ from their CO-TPR profiles. A clear correlation between the onset of $\mathrm{CO}$ oxidation with the onset of reduction of ceria surfaces by $\mathrm{CO}$ is observed, which indicates a stronger interaction of $\mathrm{CO}$ with the nanorods surfaces ${ }^{126}$. This is the result of the lower vacancy formation energy, coupled with the low coordination number of surface oxygen, the shortest surface oxygen-oxygen distance on $\{110\}$ surfaces and the presence of a large amount of defects sites on rods $^{103,134}$, which can help with formation of active oxygen species at lower temperatures. The higher reactivity of the $\{110\}$ compared to $\{111\}$ surfaces for $\mathrm{CO}$ adsorption and oxidation was also pointed out in a number of theoretical studies that addressed the formation of carbonate-like species at the expense of ceria reduction as a key step in CO oxidation ${ }^{37-38}$.

Another reaction that shows a Mars-van Krevelen type mechanism is carbon soot oxidation ${ }^{135}$. The above studies have been recently extended to soot oxidation and under these conditions a marked face dependent behavior has also been reported ${ }^{96,136-138}$. However, although it is clearly evidenced that nanoshapes influence positively carbon oxidation, the complexity of the reaction, which include catalyst-carbon contact as an additional variable, has not yet allowed to unambiguously distinguish the contribution of different effects on the overall activity (surface area, contact points, shape, size..... $)^{139-141}$. Soot oxidation over ceria-based materials occurs through the cooperation between two mutually interacting mechanisms: oxidation of soot by direct interaction between carbon and surface lattice oxygen of ceria at the carbon-ceria interface and activation of oxygen over vacancy and/or $\mathrm{Ce}^{3+}$ with formation of active oxygen species like 
peroxide or superoxides, which then spill over the carbon particles for oxidation ${ }^{142}$. Oxidation of carbon at the interface is facilitated by the higher reducibility of $\mathrm{Ce}^{4+}$ ions in nanoshapes; the resulting vacancies can then act as centers for oxygen activation, although the dependency of the oxidation rate with the formation of active oxygen species has not yet clearly disclosed. We observed a direct correlation between oxygen vacancy formation and presence of active oxygen species by in situ XPS ${ }^{142}$; however, a high number of oxygen vacancies can also lead to a higher reactivity of surface oxygen that can bring to a preferential formation of $\mathrm{O}^{2-}$ instead of $\mathrm{O}_{2}^{-}$or $\mathrm{O}_{2}^{2-}$, quenching the reaction rate with annihilation of the vacancy ${ }^{143}$. Additional studies elucidating the above aspects are therefore needed to better understand the interaction of carbon with different ceria nanoshaped materials. Total oxidation of organics like toluene and polycyclic aromatic compounds over nanoshaped ceria has also been reported recently ${ }^{88,118}$. A high oxidation activity is found with nanorods compared to nanocubes and nanopolyhedra and it has been associated to the higher number of surface oxygen defects.

However, in addition to the overall concentration of oxygen vacancies and related $\mathrm{Ce}^{3+}$, it is also the structure of these defects that plays an important role in oxidation reactions. Recent studies have shown that the distribution of oxygen vacancy defects in $\mathrm{CeO}_{2}$ nanocrystals with different shapes can alter their catalytic behavior in $\mathrm{CO}$ and other oxidation reactions. In particular, the higher activity of nanorods in $\mathrm{CO}^{105}$ and o-xylene ${ }^{144}$ oxidation was attributed to their high concentration of larger size oxygen vacancy clusters (as determined by positron annihilation lifetime spectroscopy) and to their consequent higher reducibility. The engineering of such defect clusters can be achieved either by applying specific thermal procedures ${ }^{84}$, or by utilizing appropriate synthetic methods ${ }^{105}$. The concentration and the structure of vacancy can also influence the interaction with metals and consequently affect activity of metal/ceria formulations ${ }^{145-146}$, as we will see in the next section.

Hydrogenation reactions: Oxidation reactions seem therefore to benefit from the presence of nanoshapes due to the increased reactivity of exposed $\{110\}$ and $\{100\}$ surfaces toward formation of oxygen vacancies. However, an opposite effect was found for hydrogenation reaction, where nanoparticles are more active than nanocubes ${ }^{147}$. Figure 12 compares the reactivity of nanoparticles and nanocubes in $\mathrm{CO}$ and soot oxidation and $\mathrm{C}_{2} \mathrm{H}_{2}$ hydrogenation to ethylene against the oxygen storage. It is clearly shown that while $\mathrm{CO}$ and soot oxidation are promoted by $\mathrm{CeO}_{2}$ nanocubes and by an increase of oxygen storage/vacancy formation, hydrogenation of acetylene shows and opposite behavior being favored over nanoparticles with lower oxygen 
storage. This is due to the lower reactivity of the $\{111\}$ face that limits vacancy formation and promotes hydrogenation. In contrast to oxidation reactions, hydrogenation on $\mathrm{CeO}_{2}$ is favored over low-vacancy surfaces owing to the key role of nearby oxygens on the stabilization of reactive hydroxyl intermediates ${ }^{148}$. Similarly, Zhao et al. observed enhanced propene and propyne hydrogenation activity over $\{111\} \mathrm{CeO}_{2}$ facets due to the higher density of hydroxy species with fewer oxygen vacancies ${ }^{149}$. This is also accompanied by a lower selectivity in the pairwise semihydrogenation of propyne over $\mathrm{CeO}_{2}\{111\}$ due to the presence of surface oxygen atoms that are sufficiently close and in a geometry that can accommodate the transition state ${ }^{150}$. Another example where an opposite reactivity is found is the catalytic dephosphorylation reaction, where activity of surfaces follows the trend $\{111\}>\{110\}>\{100\}$ with nanospheres and nanooctahedra perfoming better than nanorods and nanocubes ${ }^{151}$. This behavior has been associated to the surface density of oxygen vacancies derived from $\mathrm{O}_{2}$-TPD analysis, although the role of the Lewis acidity of $\mathrm{Ce}^{4+}$ cation which activate the dissociation of the $\mathrm{P}-\mathrm{O}$ bond has also been considered. Acid/base reaction: In addition to its excellent OSC properties, ceria is known also to display a rich acid-base chemistry, which can be coupled with the above redox behavior to catalyze many organic reactions ${ }^{8}$. Due to the different degree of coordinative surface unsaturation of $\mathrm{Ce}^{4+}$ and $\mathrm{O}^{2-}$ in the three major facets of $\mathrm{CeO}_{2}$, these are expected to display different acid-base properties which can result in shape dependent activity also for this type of reactions. Recently Wu et al. addressed this issue by studying the type and strength of acid-base properties over the three major facets of ceria by using nanoshaped ceria cubes, rods and octahedra ${ }^{152}$. While the results showed that only weak surface Lewis acid sites are present on ceria and are slightly dependent on the surface type, a strong surface structure dependency was found for the Lewis basic sites. A variety of carbonate species form by adsorption of $\mathrm{CO}_{2}$ over $\mathrm{CeO}_{2}$ indicating the presence of oxygen with Lewis base character with a strength that is strongly dependent on ceria shapes. This is clearly evidenced by the stability of adsorbed $\mathrm{CO}_{2}$ on the different nanoshapes and by the characteristics of adsorption of other probe molecules like $\mathrm{CHCl}_{3}$ (Figure 13). The latter can display a red shift of the $v(\mathrm{C}-\mathrm{H})$ stretching mode which is proportional to the strength of the basicity of the surface $O$ sites. The difference in acid-base site strength (coupled also with oxygen storage/release) results also in a morphology dependent activity and selectivity for reactions of various substrates with ceria shapes ${ }^{153-154}$. Thus, ethanol is easily formed in base sites of $\{100\}$ surfaces of cubes after acetaldehyde adsorption and disproportionation under temperature programmed reaction conditions, while the lower acetone production in octahedral nanoparticles 
is attributed to the lower base strength of $\{111\}$ surfaces $^{154}$. The synergism between defect sites and acid-base properties is also crucial to explain the structure-activity relationships in dimethyl carbonate synthesis with $\mathrm{CO}_{2}$ and methanol, where a clear relationship was found between activity, crystal shape and strength of acid-base sites ${ }^{109}$ (Figure 14). Other organic reactions can benefit from tailoring acid/base redox properties through the modification of ceria shapes. Thus, the coupling of redox ability with the presence of weak acid sites can explain the higher activity of nanorods in the aerobic oxidative coupling of alcohols and amines to imines ${ }^{155-156}$. Similarly, the presence of medium strength Lewis acid sites on ceria is responsible for its activity in hydrolysis reactions under liquid phase ${ }^{157}$; here the $\{111\}$ crystalline facet was more active than the $\{110\}$ and $\{100\}$ families and consequently reactivity decreased in the sequence nanopolyhedra > nanorods >nanocubes. Other cases, where the modification of crystal shape does not strongly affect activity have been reported as well ${ }^{158}$.

Therefore, in addition to the redox/defect chemistry of ceria, controlling the acid-base properties through crystal modification at nanoscale can be an additional tool for designing active and selective ceria-based catalysts.

\section{THE INFLUENCE OF NANOARCHITECTURED CERIA IN THE BEHAVIOR OF SUPPORTED METALS}

For supported metal nanoparticles, catalytic characteristics depend not only on the metal particle size, shape, composition and chemical state, but also on the role of the support. This is known as the metal-support interaction ${ }^{159}$, which has drawn growing interest since it was known that the atomic arrangement between the metal nanoparticles and the support is often directly related to the catalytic reactivity. The unique properties of ceria, such as the availability of surface oxygen species which ceria can supply to the metal site, make it an excellent support for a wide number of catalytic applications. In that way, noble metals on ceria are activated at low temperatures for many oxidation reactions ${ }^{13}$. From the study of inverse structures, where ceria nanoparticles are deposited on metal films, the metal- $\mathrm{CeO}_{2}$ interface has unambiguously been identified as the active site for many processes, such as the oxidation of CO and the water-gas shift (WGS) reaction $^{160}$.

\subsection{Effect of ceria planes on the catalytic activity and stability of $\mathrm{M} / \mathrm{CeO}_{2}$. The surface} terminations of $\mathrm{CeO}_{2}$ play a determinant role in the stabilization of metal nanoparticles as the redox capabilities of $\mathrm{CeO}_{2}$ are strongly correlated with the planes exposed. In addition, the different $\mathrm{CeO}_{2}$ nanostructures can also impact the size, morphology and interface of the metal 
nanoparticles that, furthermore, can change under different reaction environments depending on the ceria nanoshape. These factors are interdependent and can be directly or indirectly related to the planes exposed by ceria. Lin et al. ${ }^{101}$ performed aberration-corrected high angle annular dark field (HAADF) scanning transmission electron microscopy (STEM) imaging on $\mathrm{Au} / \mathrm{CeO}_{2}$ nanostructures with well-defined shapes. With atoms clearly resolved, the size, morphology and atomic interface structures between Au nanoparticles and $\mathrm{CeO}_{2}$ nanocubes and nanorods were analyzed before and after WGS. For Au nanoparticles supported over $\mathrm{CeO}_{2}$ nanocubes, the first $\mathrm{Au}$ atomic layers at the $\mathrm{Au}-\mathrm{CeO}_{2}$ interface in the as-prepared sample showed an extra-bright contrast (Figure 15), which was ascribed to the Stranski-Krastanov (SK) growth mode. The SK growth is commonly observed as a balance between a strong metal-support interaction and an equally strong metal-metal interaction. That is, the first Au monolayer metal-support interaction is stronger than the Au-Au interaction, but from the second layer onward the Au-Au is more important as stress relieves. However, after WGS, the strong metal-support interaction was lost and the Au nanoparticles coarsened. This was related to the presence of additional oxygen vacancies and $\mathrm{Ce}(\mathrm{III})$ at the $\mathrm{Au}-\mathrm{CeO}_{2}\{100\}$ interface ${ }^{101}$. This transformation had important consequences on the catalytic activity and a strong deactivation during the WGS was observed over the catalyst with Au nanoparticles supported over $\mathrm{CeO}_{2}$ nanocubes. In contrast, the $\mathrm{Au} / \mathrm{CeO}_{2}$ nanorods were constituted initially by regular Au nanoparticles and minor Au rafts, which migrated to the particles during WGS. The Au nanoparticles on the $\mathrm{CeO}_{2}$ nanorods were almost unchanged after the WGS reaction (Figure 15) and performed better than the catalyst containing $\mathrm{Au}$ nanoparticles on the $\mathrm{CeO}_{2}$ nanocubes. The better WGS performance over $\mathrm{Au} / \mathrm{CeO}$ nanorods was also reported by Si and Flytzani-Stephanopoulos ${ }^{161}$. Therefore, the different $\mathrm{CeO}_{2}$ nanostructures have a strong impact both on the size and morphology of the Au nanoparticles and, in particular, on the $\mathrm{Au}-\mathrm{CeO}_{2}$ interface through the metal-support interaction, which ultimately affect catalytic performance.

Ta et al. ${ }^{108}$ used atomic resolution environmental transmission electron microscopy (ETEM) to monitor the $\mathrm{Au}-\mathrm{CeO}_{2}$ interface of $\mathrm{Au}$ nanoparticles supported over ceria nanorods under $\mathrm{CO}$ oxidation conditions. Ceria nanorods were selected because of the facile generation of surface oxygen vacancies, which immobilize the metal nanoparticles. Under reaction conditions, the shape of the Au nanoparticles shifted from the original truncated octahedral to more rounded configurations, which reflected the restructuring of the active $\mathrm{Au}-\mathrm{CeO}_{2}$ interface. In addition, disordered $\mathrm{CeO}_{2}$ layers adjacent to the Au nanoparticles appeared under reaction, which 
increased in thickness over time (Figure 16). The chemical nature of the newly formed ceria layers was identified as reduced ceria species, which bonded the Au nanoparticles more tightly and changed the electronic state of $\mathrm{Au}$, especially the $\mathrm{Au}$ atoms at the perimeter of the $\mathrm{Au}-\mathrm{CeO}_{2}$ interface.

This particular strong metal-ceria interaction effect is likely present in other metal nanoparticles supported on ceria nanorods, as it is the case for $\mathrm{Ni} / \mathrm{CeO}_{2}$ in carbon dioxide reforming of methane, $\mathrm{Pt} / \mathrm{CeO}_{2}$ for $\mathrm{WGS}^{162}$ and $\mathrm{Ru} / \mathrm{CeO}_{2}$ for combustion of chlorobenzene. ${ }^{163}$ Du et al. ${ }^{164}$ showed that the ceria $\{100\}$ and $\{110\}$ planes had superiority for the anchoring of Ni nanoparticles, which prevented sintering of the metal phase with respect to $\mathrm{Ni} / \mathrm{CeO}_{2}$ nanopolyhedra. In the synthesis of methanol from $\mathrm{CO}_{2}$ hydrogenation over $\mathrm{Cu} / \mathrm{CeO}_{2}$, Ouyang et al. ${ }^{165}$ reported that the ceria morphology greatly affected the yield of methanol. The highest catalytic activity was found for $\mathrm{Cu}$ nanoparticles dispersed over ceria nanorods, where the strongest interaction between $\mathrm{Cu}$ and $\mathrm{CeO}_{2}$ and the highest $\mathrm{Cu}$ dispersion was also demonstrated. Zabilskiy et al. ${ }^{166}$ found a better catalytic performance for the decomposition of $\mathrm{N}_{2} \mathrm{O}$ with $\mathrm{CuO}$ nanoparticles supported on ceria nanorods, as oxygen mobility and regeneration of active $\mathrm{Cu}$ centers on the $\{100\}$ and $\{110\}$ surface planes were easier. Similarly, Liu et al. reached the same conclusion for the reduction of NO by $\mathrm{CO}^{167}$. Cui and $\mathrm{Dai}^{168}$ reported that when $\mathrm{Cu}$ was supported over ceria nanorods it was more active for carbonate hydrogenation than Cu over ceria nanocubes and nanopolyhedra also because there was a stronger interaction between $\mathrm{Cu}$ and $\mathrm{CeO}_{2}$ nanorods, resulting in a balanced distribution of $\mathrm{Cu}^{+} / \mathrm{Cu}^{0}$ species. However, Yao et al. ${ }^{169}$ reported that $\mathrm{Cu}$ nanoparticles supported on ceria nanopolyhedra showed the highest activity and stability in WGS owing to the best metallic $\mathrm{Cu}$ dispersion and strong Cu-ceria interaction, and Gamarra et al. ${ }^{170}$ showed an important enhancement of COPrOx performance of copper supported on ceria nanocubes, which was proposed to be a consequence of the interaction between $\mathrm{CuO}$ and the $\{100\}$ ceria planes. In this line, Wang et al. ${ }^{171}$ demonstrated a low reactivity in CO oxidation of Cu supported on ceria nanorods due to a strongly bound $\mathrm{Cu}-[\mathrm{Ox}]-\mathrm{Ce}$ structure by the $\{110\}$ planes of ceria, which was adverse to the formation of reduced $\mathrm{Cu}(\mathrm{I})$ active sites, whereas $\mathrm{CuO}_{\mathrm{x}}$ clusters on $\{111\}$ planes of ceria were easily reduced and stabilized, which greatly enhanced the catalytic reactivity. Other examples of the role of copper-ceria interactions in nanostructured $\mathrm{CeO}_{2}$ have been recently reviewed by Konsolakis ${ }^{172}$.

Overall, several crucial issues related to the influence of surface oxygen vacancies in ceria nanoshapes and $\mathrm{Cu} / \mathrm{CuO}$ nanoparticle shape and size in the catalytic properties of the $\mathrm{Cu}-\mathrm{CeO}_{2}$ 
system remain unclear. The reasons for the ceria nanorods being a superior metal nanoparticle support are essentially attributed to the high mobility of oxygen over the $\{110\}$ faces as well to as a strong metal-support interaction that stabilizes the metal centers. However, the procedure followed to prepare the different catalysts may result in important differences which can only be assessed by a detailed characterization at the atomic level and/or by using operando techniques. In particular, ceria nanorods may have different concentration of defects and imperfections in their lattices as a consequence of the preparation conditions employed in each case which are also reflected in differences in the proportion of the different planes exposed; as we have already discussed, in addition to $\{110\}$ and $\{100\}$ surfaces, ceria nanorods expose variable amounts of $\{111\}$ planes as well.

Surface restructuring and faceting on the performance of $\mathrm{CeO}_{2}$ as a support of metal nanoparticles have been recognized to have also a very high impact in reactivity. Tinoco et al. ${ }^{97}$ reconstructed the $\{100\}$ surfaces of ceria nanocubes into a set of $\{111\}$-bounded, zigzagged nanofacets but retaining the cubic shape by an oxidation treatment at $873 \mathrm{~K}$ (Figure 17). They demonstrated a dramatic change between conventional ceria nanocubes and restructured ceria nanocubes to fix Au nanoparticles on their surface. It is known that the $\mathrm{CeO}_{2}\{100\}$ surface is metastable and tend to reconstruct into $\{111\}$-related structures, in particular under oxygen-rich environments ${ }^{173}$, and this can be conveniently used to tune the surface of $\mathrm{CeO}_{2}$ nanostructures to accommodate metal nanoparticles. In the above work both ceria nanocubes and reconstructed nanocubes were used to prepare $\mathrm{Au} / \mathrm{CeO}_{2}$ catalysts by the deposition-precipitation (DP) method. The Au loading targeted in these preparations was $1.5 \mathrm{wt}$. \% but the catalyst prepared with the ceria nanocubes only reached 0.4 wt. \%. In contrast, the restructured ceria nanocubes accommodated an Au loading of $1.0 \mathrm{wt}$. \%. This difference was even more relevant if one considers that the surface area exposed by the restructured nanocubes was roughly half that of the initial $\mathrm{CeO}_{2}$ nanocubes. Thus, in terms of Au surface density $\left(\% \mathrm{Au} \mathrm{m}^{-2}\right)$ the difference between the two samples was 5 -fold. These results clearly indicate that the ability of ceria to nucleate and grow metal nanoparticles using the widely used methods of DP and impregnation strongly depends on the exact crystallographic nature of the facets exposed at the ceria surface. In other words, the quality of the exposed surface appears as a much more influencing factor than the total quantity of available surface. In this case, the surface restructuration imposed by the $\{111\}$ ceria nanofaceting process increased in a large extent the efficiency of Au deposition onto ceria. This can be interpreted considering that metal nanoparticles grow preferentially on surface defect sites where the contact 
area with the support can be maximized ${ }^{174}$. Then, in the valley locations of the zigzagged $\{111\}$ nanofacets the Au nanoparticles contact simultaneously at least two $\{111\}$ facets (Figure 17), this allowing to increase significantly the contact area with the ceria support as compared to the situation where Au nanoparticles sit on a flat $\{100\}$ surface. As a consequence, the restructured ceria nanocubes were much more active for the oxidation of $\mathrm{CO}$. This is in agreement with the general consensus about the key role of $\mathrm{Au}$ atoms at the perimeter of supported $\mathrm{Au}$ nanoparticles ${ }^{108}$. Cargnello et al. ${ }^{15}$ extended this conclusion to other metals (Pt, $\mathrm{Pd}$ and $\mathrm{Ni}$ ) showing that these metal nanoparticles on ceria are also active through the perimeter atoms adhered to the ceria surface.

In addition to the metal loading issue and the preferential location of metal nanoparticles over the different planes exposed by ceria, the electronic state of the deposited metal nanoparticles also depends on the facets where they anchor. This is observed by X-ray photoelectron spectroscopy (XPS) and it is sustained by DFT calculations performed on model metal clusters supported on $\mathrm{CeO}_{2}{ }^{175}$. It has been found that the electronic state of the deposited metal nanoparticles strongly depends on the reduction degree of the ceria support and, in particular, by the presence of oxygen vacancies in areas underneath the metal clusters. Then, the electronic state of metal nanoparticles anchored over $\mathrm{CeO}_{2}$ dominated by the contribution of $\{100\}$ facets are, in general, shifted in the direction of slightly negative species, whereas that of metal nanoparticles in contact with ceria $\{111\}$ facets exhibit a slightly positive oxidation state. Besides, it is well known that the presence of metal nanoparticles on top of ceria crystallites strongly modifies the reducibility of the underlying cerium oxide. All this have, obviously, an impact on catalytic behavior. Tan et al. ${ }^{176}$ studied nanoshaped $\mathrm{Pd} / \mathrm{CeO}_{2}$ catalysts for formaldehyde oxidation and found that $54 \%$ of $\mathrm{Pd}$ species on ceria nanocubes, the most active catalyst, was in the metallic state, whereas only $27 \%$ was present on ceria nanopolyhedra and all the Pd species on ceria nanorods was in oxide form. This was related with a high amount of oxygen vacancies on the ceria nanorods that generated adsorbed atomic oxygen and oxidized Pd. Also, Hu et al. ${ }^{177}$ showed that Pd on ceria nanorods mainly formed solid solution with $\mathrm{Pd}^{2+}-\mathrm{O}^{2-}-\mathrm{Ce}^{4+}$ linkages on the surface and was very active for $\mathrm{CO}$ oxidation, whereas $\mathrm{PdO}_{\mathrm{x}}$ dominated on ceria nanopolyhedra and was particularly active for propane oxidation. Therefore, the chemical states of Pd species on the ceria surface are obviously shapedependent. Surface oxygen mobility on ceria nanorods appears crucial for CO oxidation whereas $\mathrm{C}-\mathrm{H}$ activation of propane is favored on the $\{111\}$ ceria planes.

The influence of nanoshaped ceria as support of bimetallic systems has been less explored. 
Substantial changes in the metal nanoparticle structure depending upon both whether they have been exposed to oxidative or reducing conditions and the crystallographic planes exposed at the surface of the ceria support have been described for $\mathrm{RhPd} / \mathrm{CeO}_{2}$ catalysts in the steam reforming reaction of ethanol (ESR). Divins et al. ${ }^{178}$ used synchrotron radiation to perform operando X-ray diffraction in an effort to elucidate the role of the $\mathrm{CeO}_{2}$ structure on the $\mathrm{ESR}$ reaction. The bimetallic RhPd nanoparticles restructured on $\{100\}$ and $\{110\}$ ceria crystallographic planes during catalyst activation under $\mathrm{H}_{2}$ at $573 \mathrm{~K}$ and ESR due to a strong metal-support interaction, which had a positive impact on WGS performance (one of the main reactions participating in the ESR mechanism), but not on $\{111\}$ ceria planes. The use of operando characterization techniques turns to be invaluable and necessary to decipher the nature of the metal-ceria interface, which remains a controversial issue in most cases.

It should be highlighted that most comparisons reported up to now between catalysts containing metal nanoparticles supported on $\mathrm{CeO}_{2}$ with different morphologies have not properly taken into account the differences between metal nanoparticle size distributions. The main problem is the formation of different metal ensembles and structures over the different ceria nanoshapes arising from the preparation methods and/or pretreatments, which exhibit different intrinsic reactivity per se. It is encountered that the morphology of ceria strongly affects the structure of metal nanoparticles prepared from ionic salts ${ }^{179}$. Usually, $\mathrm{CeO}_{2}$ rods stabilize metal atoms and clusters whereas larger metal nanoparticles are found on $\mathrm{CeO}_{2}$ cubes $^{180}$. In this way, the discussion about the influence of ceria nanoshapes on catalytic activity is masked by different metal nanoparticle sizes and structures, which are critical factors for catalytic activity. To overcome this difficulty, Soler et al. ${ }^{181}$ studied the CO oxidation and COPrOx reaction over preformed Au metal nanoparticles supported on ceria nanocubes, nanorods and nanopolyhedra. The use of preformed Au nanoparticles allowed preparing $\mathrm{Au} / \mathrm{CeO}_{2}$ catalysts with different ceria nanoshapes but with exactly the same Au dimensions, so the effects of the ceria nanoshape on catalytic performance could be properly investigated without introducing new variables related to Au particle size and/or geometry. Interestingly, XPS revealed that Au was present in a metallic state over ceria nanocubes, as it was initially in the preformed Au nanoparticles. However, on ceria nanopolyhedra and especially on ceria nanorods, there was a very strong interaction between Au and ceria resulting in an electron density transfer from $\mathrm{Au}$ to $\mathrm{Ce}$, which ultimately led to the partial oxidation of $\mathrm{Au}$ and to the partial reduction of ceria. A clear trend between amount of $\mathrm{Ce}(\mathrm{III})$ species, amount of oxidized Au, and catalytic activity was demonstrated (Figure 18). Therefore, it 
can be unambiguously concluded that the different nanoshapes exhibited by ceria strongly affect both the structural and electronic properties of the metal nanoparticles supported on them, which ultimately determine their catalytic behavior and stability.

The bonding strength at the metal-ceria interfaces appears as key factor to control in the design of new ceria nanoshaped-supported metal catalysts. In addition, besides the surface composition and surface structure determined by the exposed crystal planes of ceria, the concentration and structure of oxygen vacancies also play a decisive role in the surface reactivity and catalytic performance, as pointed out by Esch et al. ${ }^{182}$ By employing ceria nanocubes and nanorods, Chang et al. ${ }^{145}$ demonstrated a shape-dependent interplay between oxygen vacancies and the $\mathrm{Ag}-\mathrm{CeO}_{2}$ interface, which controlled the structure and catalytic activity of $\mathrm{Ag} / \mathrm{CeO}_{2}$ catalysts for the oxidation of $\mathrm{CO}$. In particular, interaction of $\mathrm{Ag}$ with ceria nanoparticles is dependent on the presence of an appropriate ratio of large and small vacancy clusters, and this interaction also affects catalytic activity. Wang et al. ${ }^{183}$ disclosed the relationship between the concentration/type of oxygen vacancy clusters and $\mathrm{CO}_{2}$ methanation performance of $\mathrm{Ru}$ nanoparticles supported over nanoshaped ceria. It was found that Ru strongly promoted the formation of oxygen vacancies at the interface of Ru and $\{100\}$ facets of ceria nanocubes, which facilitated the activation of $\mathrm{CO}_{2}$. However, although the ordering and association of defects is certainly influencing interaction with supported metals, the exact role of oxygen vacancy clusters in ceria nanoshapes on catalytic performance still remains an open issue.

5.2 Single metals over nanoshaped ceria. Finally, we have knowledge of the presence of metal subnanometric clusters and single atoms on the $\mathrm{CeO}_{2}$ nanostructures depending on the preparation procedure used ${ }^{13}$. Until recently, we were not aware of the importance of these species as active sites for a number of reactions and wrong conclusions might have been reported by ignoring them. Metal adatoms on ceria surfaces are acquiring increasing interest for achieving high activity and selectivity for the design of efficient and economic catalysts ${ }^{184}$. Usually, single atoms on catalyst supports (SACS) are mobile and tend to aggregate into nanoparticles when heated but, recently, Jones et al. ${ }^{19}$ reported a simple method to prepare thermally stable SACs on ceria nanopolyhedra and nanorods by transferring Pt from conventional $\mathrm{Pt} / \mathrm{Al}_{2} \mathrm{O}_{3}$ to $\mathrm{CeO}_{2}$ in a physical mixture by heating at $1073 \mathrm{~K}$. Performing the synthesis at high temperature ensured a sinter-resistant, atomically dispersed catalyst. Importantly, for noble metals on ceria, single atoms and small subnanoclusters were found to boost the reduction of $\mathrm{CeO}_{2}{ }^{185}$. SACs exhibit an excellent ability to activate the lattice oxygen on the ceria surface by creating atomic M-Ox sites, which are 
highly sensitive to the ceria structure ${ }^{20}$. In addition, the special location and chemical bonding on supports also lead to unique electronic properties of single atoms different from those of metal nanoparticles. DFT calculations indicated that Pt atoms can be found preferentially adsorbed in the form of $\mathrm{Pt}(\mathrm{II})$ ions in a square-planar conformation with oxygen atoms in the $\{100\}$ facets of ceria with the concomitant reduction of two $\mathrm{Ce}^{4+}$ cations to $\mathrm{Ce}^{3+63}$. Whereas the interaction of $\mathrm{Pt}(0)$ and $\mathrm{Pt}(\mathrm{I})$ species with the ceria substrate is weaker than Pt-Pt interactions in metallic Pt nanoparticles or clusters, the $\mathrm{Pt}(\mathrm{II})$ species in the square $\mathrm{O}_{4}$ pockets on ceria should be stable enough to resist the incorporation of the $\mathrm{Pt}$ atom to a larger $\mathrm{Pt}_{\mathrm{n}}$ species. The resistance of this species to sintering and bulk diffusion was experimentally corroborated by Bruix et al. ${ }^{186}$. This structural motif can also be found on the step edges of $\{111\}$ ceria planes ${ }^{18}$ and Figueroba et al. ${ }^{187}$ claimed on the basis of DFT calculations that it can accommodate other transition metal atoms as well. The specific location of the single metal atoms on the ceria surface influences their strength of interaction with the support. Thus, step engineering in ceria nanoshapes and step decoration by atom trapping can be viewed as new tools for designing a new generation of catalysts with extraordinary performance. As an example, Figure 19 shows an aberration-corrected HAADF-STEM image reported by $\mathrm{Liu}^{184}$, corresponding to an $\mathrm{Au} / \mathrm{CeO}_{2}$ catalyst prepared by conventional wet chemistry exhibiting a large number of Ce vacancies. Because of the large number of cation vacancies, high levels of $\mathrm{Au}$ atoms could be accommodated.

\section{FINAL CONSIDERATIONS AND FUTURE DIRECTIONS}

We have shown that the manipulation of ceria shapes at nanoscale is a powerful instrument that enables a higher level of control of the catalytic behavior in numerous reactions. Forty years after its first use as an oxygen storage component by scientists at Ford Motor Company, we now precisely know which combination of particle shape and $\mathrm{CeO}_{2}$ surfaces can optimize the OSC behavior and the same is true for several other important reactions. However, parallel to this tremendous development, the use of leading-edge techniques and state of art modelling to dig inside the fundamental properties of ceria, has brought out new issues and stimulated additional questions. While the exposure of specific surfaces is a great tool in our hands to tailor activity and selectivity, the level of complexity of surface arrangements at nanoscale and their dynamic behavior, makes accurate characterization a difficult task. Therefore, a lot of work still needs to be done to understand the precise organization of surfaces under different environment conditions. 
However, a few points can be highlighted and considered when approaching catalysis with ceria nanoshapes.

(1) The representation of crystal nanoshapes as bounded by uniform surfaces, that would be useful for illustrating morphology and learning structure-activity relationships, is a rough approximation of the real situation, which might be inadequate for the precise description of the catalytic behavior. Due to the higher energy of exposed surfaces in certain nanoshapes, surface roughening and faceting and thermal reconstruction are quite common phenomena and must be considered to describe catalytic behavior. This requires advanced characterization tools often used under operando conditions.

(2) The oxygen vacancy chemistry in ceria nanoshapes is modified by the presence of different proportions of highly active surfaces and by the small size of crystals. These contributes to lower the energy of vacancy formation, which is the most demanding step in the redox of ceria. Therefore, crystal size and shape can be used to regulate the concentration of vacancies and to promote their formation, especially at lower temperature.

In addition to vacancy concentration, the structure of defects is also important to address shape/activity relationships. Different crystal shapes can promote different vacancy structure (small or large vacancy clusters or vacancy lines) with important effects in catalysis. Although the precise role of vacancy structuring in ceria has not yet fully explored, its influence in catalytic and redox properties of ceria nanoshapes cannot be neglected.

(3) A rich active oxygen chemistry exists on nanoshapes. Superoxide and peroxide species, or more generally what has been called a mixture of molecular oxygen species, $O_{x}^{q}$ (with $\mathrm{x}=2$ or 3 and $q=0,-1$, or -2 ) are observed on nanorods and nanocubes in different proportions that might be related to the types of defects and the presence of isolated or clustered vacancies. The higher activity of these species toward $\mathrm{CO}$ and soot oxidation is well established and should be considered when making structure-activity relationships. To this end a special attention should be given to the relation between formation of superoxide in small "vacancy free" nanoparticles and oxygen storage capacity which can be important specifically to promote low temperature reactivity.

(4) With the recent capability of rational designing and developing shape-controlled ceria nanostructures it is expected that breakthroughs in metal-support interactions will significantly advance the development of practical catalysts based on nanoshaped $\mathrm{CeO}_{2}$ for broad technological application. The bonding strength at the metal-ceria interfaces appears as key factor 
to control in the design of new ceria nanoshaped-supported metal catalysts. In addition, besides the surface composition and surface structure determined by the exposed crystal planes of ceria, the concentration and structure of oxygen vacancies also play a decisive role in the surface reactivity and catalytic performance of ceria-supported metal nanoparticles.

(5) Engineering ceria shape may be critical to overcome one of the grand challenges in catalysis by supported single metal atoms, which is the anchoring of specific metal atoms to a support with high number density of metal atoms and stability at high temperature. With a proper ceria surface design, it should be possible to place with high specificity single metal atoms into an atomically defined environment. Therefore, by manipulating the interaction between single metal atoms with particular sites on a ceria nanoshaped support it may be possible to tune a precise energy for the resulting system of single metal atom plus the surrounding atoms on the support, which would ultimately lead to an unprecedented success in the control of catalytic performance.

Acknowledgements: AT acknowledges the support from Interreg Project (Coat4Cata Project Nr. ITAT 1019). JL is Serra Húnter Fellow and is grateful to ICREA Academia program and MINECO/FEDER grant ENE2015-63969-R. The authors are indebted to Prof. Stefano Fabris for the very helpful discussion. The authors also acknowledge extensive discussions with their respective research group members.

\section{REFERENCES}

1. Zhou, K. B.; Li, Y. D. Angew. Chem. Int. Ed. 2012, 51, 602-613.

2. Wu, Z.; Overbury, S. H., in Catalysis by Materials with Well-Defined Structures 1st ed; Elsevier, 2015.

3. Tian, N.; Zhou, Z. Y.; Sun, S. G.; Ding, Y.; Wang, Z. L. Science 2007, 316, 732-735.

4. Zhou, Z. Y.; Tian, N.; Li, J. T.; Broadwell, I.; Sun, S. G. Chem. Soc. Rev. 2011, 40, 4167-4185.

5. Wang, Y.; Woll, C. Chem. Soc. Rev. 2017, 46, 1875-1932.

6. Trovarelli, A. Catal. Rev.-Sci. Eng. 1996, 38, 439-520.

7. McCabe, R. W.; Trovarelli, A. Appl. Catal. B: Environ. 2016, 197, 1.

8. Vivier, L.; Duprez, D. Chemsuschem 2010, 3, 654-678.

9. Montini, T.; Melchionna, M.; Monai, M.; Fornasiero, P. Chem. Rev. 2016, 116, 5987-6041.

10. Gorte, R. J. Aiche Journal 2010, 56, 1126-1135.

11. Trovarelli, A.; Fornasiero, P., in Catalysis by Ceria and Related Materials, 2nd ed.; Imperial College Press: London, 2013.

12. Carrettin, S.; Concepcion, P.; Corma, A.; Nieto, J. M. L.; Puntes, V. F. Angew. Chem. Int. Ed. 2004, 43, 2538-2540.

13. Fu, Q.; Saltsburg, H.; Flytzani-Stephanopoulos, M. Science 2003, 301, 935-938.

14. Divins, N. J.; Angurell, I.; Escudero, C.; Perez-Dieste, V.; Llorca, J. Science 2014, 346, 620-623. 
15. Cargnello, M.; Doan-Nguyen, V. V. T.; Gordon, T. R.; Diaz, R. E.; Stach, E. A.; Gorte, R. J.; Fornasiero, P.; Murray, C. B. Science 2013, 341, 771-773.

16. Rodriguez, J. A.; Grinter, D. C.; Liu, Z.; Palomino, R. M.; Senanayake, S. D. Chem. Soc. Rev. 2017, 46, 1824-1841.

17. Farmer, J. A.; Campbell, C. T. Science 2010, 329, 933-936.

18. Dvorak, F.; Farnesi Camellone, M.; Tovt, A.; Tran, N. D.; Negreiros, F. R.; Vorokhta, M.; Skala, T.; Matolinova, I.; Myslivecek, J.; Matolin, V.; Fabris, S. Nat. Commun. 2016, 7, 10801.

19. Jones, J.; Xiong, H. F.; Delariva, A. T.; Peterson, E. J.; Pham, H.; Challa, S. R.; Qi, G. S.; Oh, S.; Wiebenga, M. H.; Hernandez, X. I. P.; Wang, Y.; Datye, A. K. Science 2016, 353, 150-154.

20. Vayssilov, G. N.; Lykhach, Y.; Migani, A.; Staudt, T.; Petrova, G. P.; Tsud, N.; Skala, T.; Bruix, A.; Illas, F.; Prince, K. C.; Matolin, V.; Neyman, K. M.; Libuda, J. Nat. Mater. 2011, 10, 310315.

21. Mudiyanselage, K.; Senanayake, S. D.; Feria, L.; Kundu, S.; Baber, A. E.; Graciani, J.; Vidal, A. B.; Agnoli, S.; Evans, J.; Chang, R.; Axnanda, S.; Liu, Z.; Sanz, J. F.; Liu, P.; Rodriguez, J. A.; Stacchiola, D. J. Angew. Chem. Int. Ed. 2013, 52, 5101-5105.

22. Sayle, T. X. T.; Parker, S. C.; Catlow, C. R. A. Surf. Sci. 1994, 316, 329-336.

23. Conesa, J. C. Surf. Sci. 1995, 339, 337-352.

24. Vantomme, A.; Yuan, Z. Y.; Du, G. H.; Su, B. L. Langmuir 2005, 21, 1132-1135.

25. Yu, T. Y.; Joo, J.; Park, Y. I.; Hyeon, T. Angew. Chem. Int. Ed. 2005, 44, 7411-7414.

26. Mai, H. X.; Sun, L. D.; Zhang, Y. W.; Si, R.; Feng, W.; Zhang, H. P.; Liu, H. C.; Yan, C. H. J. Phys. Chem. B 2005, 109, 24380-24385.

27. Yuan, Q.; Duan, H. H.; Li, L. L.; Sun, L. D.; Zhang, Y. W.; Yan, C. H. J. Colloid Interface Sci. 2009, 335, 151-167.

28. Du, N.; Zhang, H.; Chen, B. G.; Ma, X. Y.; Yang, D. R. J. Phys. Chem. C 2007, 111, 12677-12680.

29. Hirano, M.; Etsuro, K. J. Amer. Ceram. Soc. 1996, 79, 777-780.

30. Wang, Z. L.; Feng, X. D. J. Phys. Chem. B 2003, 107, 13563-13566.

31. Huang, P. X.; Wu, F.; Zhu, B. L.; Gao, X. P.; Zhu, H. Y.; Yan, T. Y.; Huang, W. P.; Wu, S. H.; Song, D. Y. J. Phys. Chem. B 2005, 109, 19169-19174.

32. Pan, C. S.; Zhang, D. S.; Shi, L. Y.; Fang, J. H. Eur. J. Inorg. Chem. 2008, 2429-2436.

33. Han, W. Q.; Wu, L. J.; Zhu, Y. M. J. Am. Chem. Soc. 2005, 127, 12814-12815.

34. Ho, C. M.; Yu, J. C.; Kwong, T.; Mak, A. C.; Lai, S. Y. Chem. Mater. 2005, 17, 4514-4522.

35. Zhou, K. B.; Wang, X.; Sun, X. M.; Peng, Q.; Li, Y. D. J. Catal. 2005, 229, 206-212.

36. Aneggi, E.; Llorca, J.; Boaro, M.; Trovarelli, A. J. Catal. 2005, 234, 88-95.

37. Huang, M.; Fabris, S. J. Phys. Chem. C 2008, 112, 8643-8648.

38. Chen, F.; Liu, D.; Zhang, J.; Hu, P.; Gong, X. Q.; Lu, G. Phys Chem Chem Phys 2012, 14, 1657316580.

39. Zhang, D. S.; Du, X. J.; Shi, L. Y.; Gao, R. H. Dalton Trans. 2012, 41, 14455-14475.

40. Sun, C.; Li, H.; Chen, L. Energy Environ. Sci. 2012, 5, 8475-8505.

41. Huang, W. X.; Gao, Y. X. Catal. Sci. Tech. 2014, 4, 3772-3784.

42. Sheng, D.; Wu, Z.; Zhen-An, Q. ChemSusChem 2013, 6, 1821-1833.

43. Ta, N.; Liu, J. Y.; Shen, W. J. Chin. J. Catal. 2013, 34, 838-850.

44. Wu, K.; Sun, L.-D.; Yan, C.-H. Adv. Enery. Mater. 2016, 6, 1600501.

45. Melchionna, M.; Fornasiero, P. Mater. Today 2014, 17, 349-357.

46. Nolan, M.; Grigoleit, S.; Sayle, D. C.; Parker, S. C.; Watson, G. W. Surf. Sci. 2005, 576, 217229.

47. Branda, M. M.; Ferullo, R. M.; Causa, M.; Illas, F. J. Phys. Chem. C 2011, 115, 3716-3721.

48. Paier, J.; Penschke, C.; Sauer, J. Chem. Rev. 2013, 113, 3949-3985.

49. Mullins, D. R.; Albrecht, P. M.; Calaza, F. Top. Catal. 2013, 56, 1345-1362. 
50. Mullins, D. R. Surf. Sci. Rep. 2015, 70, 42-85.

51. Möbus, G.; Saghi, Z.; Sayle, D. C.; Bhatta, U. M.; Stringfellow, A.; Sayle, T. X. T. Adv. Funct. Mater. 2011, 21, 1971-1976.

52. Capdevila-Cortada, M.; Lopez, N. Nat. Mater. 2017, 16, 328-335.

53. Norenberg, H.; Harding, J. H. Surf. Sci. 2001, 477, 17-24.

54. Nolan, M.; Parker, S. C.; Watson, G. W. Surf. Sci. 2005, 595, 223-232.

55. Baudin, M.; Wojcik, M.; Hermansson, K. Surf. Sci. 2000, 468, 51-61.

56. Skorodumova, N. V.; Baudin, M.; Hermansson, K. Phys. Rev. B 2004, 69, 075401.

57. Tsunekawa, S.; Sahara, R.; Kawazoe, Y.; Ishikawa, K. Appl. Surf. Sci. 1999, 152, 53-56.

58. Tsunekawa, S.; Wang, J. T.; Kawazoe, Y. J. Alloy. Comp. 2006, 408, 1145-1148.

59. Zhou, X. D.; Huebner, W. Appl. Phys. Lett. 2001, 79, 3512-3514.

60. Dutta, P.; Pal, S.; Seehra, M. S.; Shi, Y.; Eyring, E. M.; Ernst, R. D. Chem. Mater. 2006, 18, 5144-5146.

61. Hailstone, R. K.; Difrancesco, A. G.; Leong, J. G.; Allston, T. D.; Reed, K. J. J. Phys. Chem. C 2009, 113, 15155-15159.

62. Migani, A.; Vayssilov, G. N.; Bromley, S. T.; Illas, F.; Neyman, K. M. J. Mater. Chem. 2010, 20, 10535-10546.

63. Bruix, A.; Neyman, K. M. Catal. Lett. 2016, 146, 2053-2080.

64. Sk, M. A.; Kozlov, S. M.; Lim, K. H.; Migani, A.; Neyman, K. M. J. Mater. Chem. A 2014, 2, 18329-18338.

65. Xu, J. H.; Harmer, J.; Li, G. Q.; Chapman, T.; Collier, P.; Longworth, S.; Tsang, S. C. Chem. Commun. 2010, 46, 1887-1889.

66. Migani, A.; Neyman, K. M.; Illas, F.; Bromley, S. T. J. Chem. Phys. 2009, 131, 064701.

67. Huang, X.; Beck, M. J. Chem. Mater. 2015, 27, 5840-5844.

68. Huang, X.; Beck, M. J. Computat. Mater. Sci. 2014, 91, 122-133.

69. Kullgren, J.; Hermansson, K.; Broqvist, P. J. Phys. Chem. Lett. 2013, 4, 604-608.

70. Guzman, J.; Carrettin, S.; Corma, A. J. Am. Chem. Soc. 2005, 127, 3286-3287.

71. Burda, C.; Chen, X. B.; Narayanan, R.; El-Sayed, M. A. Chem. Rev. 2005, 105, 1025-1102.

72. Tan, J. P. Y.; Tan, H. R.; Boothroyd, C.; Foo, Y. L.; He, C. B.; Lin, M. J. Phys. Chem. C 2011, 115, 3544-3551.

73. Zhang, M. L.; Chen, Y.; Qiu, C. J.; Fan, X. F.; Chen, C. L.; Wang, Z. C. Physica E-Low Dimens. Syst. Nanostruct. 2014, 64, 218-223.

74. Florea, I.; Feral-Martin, C.; Majimel, J.; Ihiawakrim, D.; Hirlimann, C.; Ersen, O. Cryst. Growth Des. 2013, 13, 1110-1121.

75. Yan, Z. G.; Yan, C. H. J. Mater. Chem. 2008, 18, 5046-5059.

76. Yang, S. W.; Gao, L. J. Am. Chem. Soc. 2006, 128, 9330-9331.

77. Zhang, J.; Ohara, S.; Umetsu, M.; Naka, T.; Hatakeyama, Y.; Adschiri, T. Adv. Mater. 2007, 19, 203-206.

78. Dang, F.; Kato, K.; Imai, H.; Wada, S.; Haneda, H.; Kuwabara, M. Cryst. Growth Des. 2010, 10, 4537-4541.

79. Pan, C.; Zhang, D.; Shi, L. J. Solid State Chem. 2008, 181, 1298-1306.

80. Fuentes, R. O.; Acuna, L. M.; Zimic, M. G.; Lamas, D. G.; Sacanell, J. G.; Leyva, A. G.; Baker, R. T. Chem. Mater. 2008, 20, 7356-7363.

81. Yan, L.; Yu, R. B.; Chen, J.; Xing, X. R. Cryst. Growth Des. 2008, 8, 1474-1477.

82. Tang, C. C.; Bando, Y.; Liu, B. D.; Golberg, D. Adv. Mater. 2005, 17, 3005-3009.

83. Zhou, K. B.; Yang, Z. Q.; Yang, S. Chem. Mater. 2007, 19, 1215-1217.

84. Lawrence, N. J.; Brewer, J. R.; Wang, L.; Wu, T. S.; Wells-Kingsbury, J.; Ihrig, M. M.; Wang, G. H.; Soo, Y. L.; Mei, W. N.; Cheung, C. L. Nano Lett. 2011, 11, 2666-2671. 
85. Wang, X.; Li, Y. D. Angew. Chem. Int. Ed. 2002, 41, 4790-4793.

86. Wu, Q.; Zhang, F.; Xiao, P.; Tao, H. S.; Wang, X. Z.; Hu, Z.; Lu, Y. N. J. Phys. Chem. C 2008, 112, 17076-17080.

87. Wang, W.; Howe, J. Y.; Li, Y. A.; Qiu, X. F.; Joy, D. C.; Paranthaman, M. P.; Doktycz, M. J.; Gu, B. H. J. Mater. Chem. 2010, 20, 7776-7781.

88. Torrente-Murciano, L.; Gilbank, A.; Puertolas, B.; Garcia, T.; Solsona, B.; Chadwick, D. Appl. Catal. B: Environ. 2013, 132, 116-122.

89. Yu, R.; Yan, L.; Zheng, P.; Chen, J.; Xing, X. R. J. Phys. Chem. C 2008, 112, 19896-19900.

90. Ji, Z.; Wang, X.; Zhang, H.; Lin, S.; Meng, H.; Sun, B.; George, S.; Xia, T.; Nel, A. E.; Zink, J. I. ACS Nano 2012, 6, 5366-5380.

91. Chen, G. Z.; Xu, C. X.; Song, X. Y.; Xu, S. L.; Ding, Y.; Sun, S. X. Cryst. Growth Des. 2008, 8, 4449-4453.

92. Agarwal, S.; Mojet, B. L.; Lefferts, L.; Datye, A. K., In Catalysis by Materials with Well-Defined Structures, Wu, Z.; Overbury, S. H., Eds. Elsevier: 2015; pp 31-70.

93. Revoy, M. N.; Scott, R. W. J.; Grosvenor, A. P. J. Phys. Chem. C 2013, 117, 10095-10105.

94. Lin, Y. Y.; Wu, Z. L.; Wen, J. G.; Poeppelmeier, K. R.; Marks, L. D. Nano Lett. 2014, 14, 191196.

95. Bhatta, U. M.; Reid, D.; Sakthivel, T.; Sayle, T. X. T.; Sayle, D.; Molinari, M.; Parker, S. C.; Ross, I. M.; Seal, S.; Mobus, G. J. Phys. Chem. C 2013, 117, 24561-24569.

96. Aneggi, E.; Wiater, D.; de Leitenburg, C.; Llorca, J.; Trovarelli, A. ACS Catal. 2014, 4, 172-181.

97. Tinoco, M.; Fernandez-Garcia, S.; Lopez-Haro, M.; Hungria, A. B.; Chen, X.; Blanco, G.; PerezOmil, J. A.; Collins, S. E.; Okuno, H.; Calvino, J. J. ACS Catal. 2015, 5, 3504-3513.

98. Jacobsen, S. N.; Helmersson, U.; Erlandsson, R.; Skarman, B.; Wallenberg, L. R. Surf. Sci. 1999, 429, 22-33.

99. Develos-Bagarinao, K.; Yamasaki, H.; Nakagawa, Y.; Nie, J. C.; Sohma, M.; Kumagai, T. Nanotechnology 2007, 18, 165605.

100. Sayle, T. X. T.; Parker, S. C.; Sayle, D. C. Chem. Commun. 2004, 2438-2439.

101. Lin, Y.; Wu, Z.; Wen, J.; Ding, K.; Yang, X.; Poeppelmeier, K. R.; Marks, L. D. Nano Lett. 2015, $15,5375-5381$.

102. Lu, X. H.; Zhai, T.; Cui, H. N.; Shi, J. Y.; Xie, S. L.; Huang, Y. Y.; Liang, C. L.; Tong, Y. X. J. Mater. Chem. 2011, 21, 5569-5572.

103. Wu, Z. L.; Li, M. J.; Howe, J.; Meyer, H. M.; Overbury, S. H. Langmuir 2010, 26, 16595-16606.

104. Désaunay, T.; Bonura, G.; Chiodo, V.; Freni, S.; Couzinié, J. P.; Bourgon, J.; Ringuedé, A.; Labat, F.; Adamo, C.; Cassir, M. J. Catal. 2013, 297, 193-201.

105. Liu, X. W.; Zhou, K. B.; Wang, L.; Wang, B. Y.; Li, Y. D. J. Am. Chem. Soc. 2009, 131, 31403141.

106. Agarwal, S.; Lefferts, L.; Mojet, B. L.; Ligthart, D. A. J. M.; Hensen, E. J. M.; Mitchell, D. R. G.; Erasmus, W. J.; Anderson, B. G.; J., O. E.; Neethling, J. H.; Datye, A. K. Chemsuschem 2013, 6, 1898-1906.

107. Tana; Zhang, M. L.; Li, J.; Li, H. J.; Li, Y.; Shen, W. J. Catal. Today 2009, 148, 179-183.

108. Ta, N.; Liu, J. J.; Chenna, S.; Crozier, P. A.; Li, Y.; Chen, A.; Shen, W. J. Am. Chem. Soc. 2012, 134, 20585-20588.

109. Wang, S. P.; Zhao, L. F.; Wang, W.; Zhao, Y. J.; Zhang, G. L.; Ma, X. B.; Gong, J. L. Nanoscale 2013, 5, 5582-5588.

110. Yang, C.; Yu, X.; Heissler, S.; Nefedov, A.; Colussi, S.; Llorca, J.; Trovarelli, A.; Wang, Y.; Woll, C. Angew. Chem. Int. Ed. 2017, 56, 375-379.

111. Sakthivel, T. S.; Reid, D. L.; Bhatta, U. M.; Mobus, G.; Sayle, D. C.; Seal, S. Nanoscale 2015, 7, 5169-5177. 
112. Bugayeva, N. Mater. Res. Soc. Symp. Proc. 2005, 876E, R8.46.1-R8.46.6.

113. Wang, D. Y.; Kang, Y. J.; Doan-Nguyen, V.; Chen, J.; Kungas, R.; Wieder, N. L.; Bakhmutsky, K.; Gorte, R. J.; Murray, C. B. Angew. Chem. Int. Ed. 2011, 50, 4378-4381.

114. Li, J.; Zhang, Z. Y.; Tian, Z. M.; Zhou, X. M.; Zheng, Z. P.; Ma, Y. Y.; Qu, Y. Q. J. Mater. Chem. A 2014, 2, 16459-16466.

115. Sreeremya, T. S.; Krishnan, A.; Remani, K. C.; Patil, K. R.; Brougham, D. F.; Ghosh, S. ACS Appl. Mater. Interfaces 2015, 7, 8545-8555.

116. Li, Y.; Wei, Z. H.; Gao, F.; Kovarik, L.; Peden, C. H. F.; Wang, Y. J. Catal. 2014, 315, 15-24.

117. Kovacevic, M.; Mojet, B. L.; van Ommen, J. G.; Lefferts, L. Catal. Lett. 2016, 146, 770-777.

118. Lopez, J. M.; Gilbank, A. L.; Garcia, T.; Solsona, B.; Agouram, S.; Torrente-Murciano, L. Appl. Catal. B: Environ. 2015, 174, 403-412.

119. Ishikawa, Y.; Takeda, M.; Tsukimoto, S.; Nakayama, K. S.; Asao, N. Adv. Mater. 2016, 28, 1467-1471.

120. Zhang, J.; Kumagai, H.; Yamamura, K.; Ohara, S.; Takami, S.; Morikawa, A.; Shinjoh, H.; Kaneko, K.; Adschiri, T.; Suda, A. Nano Lett. 2011, 11, 361-364.

121. Huang, M.; Fabris, S. Phys. Rev. B 2007, 75, 081404.

122. Preda, G.; Migani, A.; Neyman, K. M.; Bromley, S. T.; Illas, F.; Pacchioni, G. J. Phys. Chem. C 2011, 115, 5817-5822.

123. Zhao, Y.; Teng, B.T.; Wen, X.D.; Zhao, Y.; Chen, Q.P.; Zhao, L.H.; Luo, M.F. J. Phys. Chem. C 2012, 116, 15986-15991.

124. Renuka, N. K.; Harsha, N.; Divya, T. RSC Advances 2015, 5, 38837-38841.

125. Fabris, S., Personal Communication 2017.

126. Wu, Z. L.; Li, M. J.; Overbury, S. H. J. Catal. 2012, 285, 61-73.

127. Wang, X.; Jiang, Z.; Zheng, B.; Xie, Z.; Zheng, L. CrystEngComm 2012, 14, 7579-7582.

128. Zhou, H. P.; Zhang, Y. W.; Si, R.; Zhang, L. S.; Song, W. G.; Yan, C. H. J. Phys. Chem. C 2008, 112, 20366-20374.

129. Li, J. F.; Lu, G. Z.; Li, H. F.; Wang, Y. Q.; Guo, Y.; Guo, Y. L. J. Colloid Interface Sci. 2011, 360, 93-99.

130. Cui, R.; Lu, W.; Zhang, L.; Yue, B.; Shen, S. J. Phys. Chem. C 2009, 113, 21520-21525.

131. Renuka, N. K.; Praveen, A. K.; Aniz, C. U. Micropor. Mesopor. Mat. 2013, 169, 35-41.

132. Li, J.; Zhang, Z.; Gao, W.; Zhang, S.; Ma, Y.; Qu, Y. ACS Appl. Mater. Interfaces 2016, 8, 2298822996.

133. Lykaki, M.; Pachatouridou, E.; Iliopoulou, E.; Carabineiro, S. A. C.; Konsolakis, M. RSC Advances 2017, 7, 6160-6169.

134. Agarwal, S.; Zhu, X.; Hensen, E. J. M.; Lefferts, L.; Mojet, B. L. J. Phys. Chem. C 2014, 118, 4131-4142.

135. Bueno-Lopez, A. Appl. Catal. B: Environ. 2014, 146, 1-11.

136. Aneggi, E.; de Leitenburg, C.; Llorca, J.; Trovarelli, A. Catal. Today 2012, 197, 119-126.

137. Piumetti, M.; Bensaid, S.; Russo, N.; Fino, D. Appl. Catal. B: Environ. 2015, 165, 742-751.

138. Zhang, W.; Niu, X. Y.; Chen, L. Q.; Yuan, F. L.; Zhu, Y. J. Sci. Rep. 2016, 6, 29062.

139. Piumetti, M.; van der Linden, B.; Makkee, M.; Miceli, P.; Fino, D.; Russo, N.; Bensaid, S. Appl. Catal. B: Environ. 2016, 199, 96-107.

140. Aneggi, E.; de Leitenburg, C.; Trovarelli, A. Catal. Today 2012, 181, 108-115.

141. Aneggi, E.; Rico-Perez, V.; De Leitenburg, C.; Maschio, S.; Soler, L.; Llorca, J.; Trovarelli, A. Angew. Chem. Int. Ed. 2015, 54, 14040-14043.

142. Soler, L.; Casanovas, A.; Escudero, C.; Perez-Dieste, V.; Aneggi, E.; Trovarelli, A.; Llorca, J. ChemCatChem 2016, 8, 2748-2751. 
143. Liu, S.; Wu, X. D.; Tang, J.; Cui, P. Y.; Jiang, X. Q.; Chang, C. G.; Liu, W.; Gao, Y. X.; Li, M.; Weng, D. Catal. Today 2017, 281, 454-459.

144. Wang, L.; Wang, Y. F.; Zhang, Y.; Yu, Y. B.; He, H.; Qin, X. B.; Wang, B. Y. Catal. Sci. Tech. 2016, 6, 4840-4848.

145. Chang, S.; Li, M.; Hua, Q.; Zhang, L.; Ma, Y.; Ye, B.; Huang, W. J. Catal. 2012, 293, 195-204.

146. Huang, W. Acc. Chem. Res. 2016, 49, 520-527.

147. Vile, G.; Colussi, S.; Krumeich, F.; Trovarelli, A.; Perez-Ramirez, J. Angew. Chem. Int. Ed. 2014, 53, 12069-12072.

148. Vile, G.; Bridier, B.; Wichert, J.; Perez-Ramirez, J. Angew. Chem. Int. Ed. 2012, 51, 8620-8623.

149. Zhao, E. W.; Zheng, H. B.; Zhou, R. H.; Hagelin-Weaver, H. E.; Bowers, C. R. Angew. Chem. Int. Ed. 2015, 54, 14270-14275.

150. Zhao, E. W.; Xin, Y.; Hagelin-Weaver, H. E.; Bowers, C. R. Chemcatchem 2016, 8, 2197-2201.

151. Manto, M. J.; Xie, P. F.; Wang, C. ACS Catal. 2017, 7, 1931-1938.

152. Wu, Z. L.; Mann, A. K. P.; Li, M. J.; Overbury, S. H. J. Phys. Chem. C 2015, 119, 7340-7350.

153. Li, M.; Wu, Z.; Overbury, S. H. J. Catal. 2013, 306, 164-176.

154. Mann, A. K. P.; Wu, Z. L.; Calaza, F. C.; Overbury, S. H. ACS Catal. 2014, 4, 2437-2448.

155. Geng, L. L.; Song, J. L.; Zhou, Y. H.; Xie, Y.; Huang, J. H.; Zhang, W. X.; Peng, L. M.; Liu, G. Chem. Commun. 2016, 52, 13495-13498.

156. Zhang, Z.; Wang, Y.; Wang, M.; Lü, J.; Li, L.; Zhang, Z.; Li, M.; Jiang, J.; Wang, F. Chin. J. Catal. 2015, 36, 1623-1630.

157. Wang, Y.; Wang, F.; Song, Q.; Xin, Q.; Xu, S.; Xu, J. J. Am. Chem. Soc. 2013, 135, 1506-1515.

158. Snell, R. W.; Hakim, S. H.; Dumesic, J. A.; Shanks, B. H. Appl. Catal. A Gen. 2013, 464, 288295.

159. Ahmadi, M.; Mistry, H.; Cuenya, B. R. J. Phys. Chem. Lett. 2016, 7, 3519-3533.

160. Rodriguez, J. A.; Senanayake, S. D.; Stacchiola, D.; Liu, P.; Hrbek, J. Acc. Chem. Res. 2014, 47, 773-782.

161. Si, R.; Flytzani-Stephanopoulos, M. Angew. Chem. Int. Ed. 2008, 47, 2884-2887.

162. Torrente-Murciano, L.; Garcia-Garcia, F. R. Catal. Commun. 2015, 71, 1-6.

163. Huang, H.; Dai, Q. G.; Wang, X. Y. Appl. Catal. B: Environ. 2014, 158, 96-105.

164. Du, X.; Zhang, D.; Shi, L.; Gao, R.; Zhang, J. J. Phys. Chem. C 2012, 116, 10009-10016.

165. Ouyang, B.; Tan, W.; Bing, L. Catal. Commun. 2017, 95, 36-39.

166. Zabilskiy, M.; Djinovic, P.; Tchernychova, E.; Tkachenko, O. P.; Kustov, L. M.; Pintar, A. ACS Catal. 2015, 5, 5357-5365.

167. Liu, L.; Yao, Z.; Deng, Y.; Gao, F.; Liu, B.; Dong, L. Chemcatchem 2011, 3, 978-989.

168. Cui, Y. Y.; Dai, W. L. Catal. Sci. Tech. 2016, 6, 7752-7762.

169. Yao, S. Y.; Xu, W. Q.; Johnston-Peck, A. C.; Zhao, F. Z.; Liu, Z. Y.; Luo, S.; Senanayake, S. D.; Martinez-Arias, A.; Liu, W. J.; Rodriguez, J. A. Phys. Chem. Chem. Phys. 2014, 16, 1718317195.

170. Gamarra, D.; Camara, A. L.; Monte, M.; Rasmussen, S. B.; Chinchilla, L. E.; Hungria, A. B.; Munuera, G.; Gyorffy, N.; Schay, Z.; Corberan, V. C.; Conesa, J. C.; Martinez-Arias, A. Appl. Catal. B: Environ. 2013, 130, 224-238.

171. Wang, W.-W.; Yu, W.-Z.; Du, P.-P.; Xu, H.; Jin, Z.; Si, R.; Ma, C.; Shi, S.; Jia, C.-J.; Yan, C.-H. ACS Catal. 2017, 7, 1313-1329.

172. Konsolakis, M. Appl. Catal. B: Environ. 2016, 198, 49-66.

173. Fronzi, M.; Soon, A.; Delley, B.; Traversa, E.; Stampfl, C. J. Chem. Phys. 2009, 131, 104701.

174. Gonzalez, J. C.; Hernandez, J. C.; Lopez-Haro, M.; del Rio, E.; Delgado, J. J.; Hungria, A. B.; Trasobares, S.; Bernal, S.; Midgley, P. A.; Calvino, J. J. Angew. Chem. Int. Ed. 2009, 48, 53135315. 
175. Kim, H. Y.; Lee, H. M.; Henkelman, G. J. Am. Chem. Soc. 2012, 134, 1560-1570.

176. Tan, H. Y.; Wang, J.; Yu, S. Z.; Zhou, K. B. Environ. Sci. Tech. 2015, 49, 8675-8682.

177. Hu, Z.; Liu, X.; Meng, D.; Guo, Y.; Guo, Y.; Lu, G. ACS Catal. 2016, 6, 2265-2279.

178. Divins, N. J.; Casanovas, A.; Xu, W.; Senanayake, S. D.; Wiater, D.; Trovarelli, A.; Llorca, J. Catal. Today 2015, 253, 99-105.

179. Baron, M.; Bondarchuk, O.; Stacchiola, D.; Shaikhutdinov, S.; Freund, H. J. J. Phys. Chem. C 2009, 113, 6042-6049.

180. Yi, N.; Si, R.; Saltsburg, H.; Flytzani-Stephanopoulos, M. Appl. Catal. B: Environ. 2010, 95, 8792.

181. Soler, L.; Casanovas, A.; Urrich, A.; Angurell, I.; Llorca, J. Appl. Catal. B: Environ. 2016, 197, 47-55.

182. Esch, F.; Fabris, S.; Zhou, L.; Montini, T.; Africh, C.; Fornasiero, P.; Comelli, G.; Rosei, R. Science 2005, 309, 752-755.

183. Wang, F.; Li, C. M.; Zhang, X. Y.; Wei, M.; Evans, D. G.; Duan, X. J. Catal. 2015, 329, 177-186.

184. Liu, J. ACS Catal. 2017, 7, 34-59.

185. Yang, X. F.; Wang, A. Q.; Qiao, B. T.; Li, J.; Liu, J. Y.; Zhang, T. Acc. Chem. Res. 2013, 46, 17401748.

186. Bruix, A.; Lykhach, Y.; Matolinova, I.; Neitzel, A.; Skala, T.; Tsud, N.; Vorokhta, M.; Stetsovych, V.; Sevcikova, K.; Myslivecek, J.; Fiala, R.; Vaclavu, M.; Prince, K. C.; Bruyere, S.; Potin, V.; Illas, F.; Matolin, V.; Libuda, J.; Neyman, K. M. Angew. Chem. Int. Ed. 2014, 53, 10525-10530.

187. Figueroba, A.; Kovacs, G.; Bruix, A.; Neyman, K. M. Catal. Sci. Tech. 2016, 6, 6806-6813. 
Table 1: Characteristics of low index surfaces of $\mathrm{CeO}_{2}$

\begin{tabular}{cccc}
\hline & 111 & 110 & 100 \\
\cline { 2 - 4 } Coordination number & $\mathrm{O}(3), \mathrm{Ce}(7)$ & $\mathrm{O}(3), \mathrm{Ce}(6)$ & $\mathrm{O}(2), \mathrm{Ce}(6)$ \\
Coordinative unsaturated sites & $\mathrm{O}(1), \mathrm{Ce}(1)$ & $\mathrm{O}(1), \mathrm{Ce}(2)$ & $\mathrm{O}(2), \mathrm{Ce}(2)$ \\
Surface energy $(\mathrm{eV})^{\mathrm{a}}$ & $0.69(0.68)$ & $1.26(1.01)$ & $2.05(1.41)$ \\
Oxygen vacancy & 2.60 & 1.99 & 2.27 \\
formation energy $(\mathrm{eV})^{\mathrm{b}}$ & & & \\
\hline
\end{tabular}

anrelaxed and (relaxed) values of surface energies obtained from ab initio DFT calculations ${ }^{46}$. bVacancy formation energy calculated applying DFT corrected for on-site Coulomb interactions DFT+U ${ }^{54}$.

Table 2: OSC of different nanoshapes ${ }^{a}$

\begin{tabular}{lccc}
\hline & $\begin{array}{c}\text { OSC } \\
(\mu \mathrm{mol} \mathrm{O} / \mathrm{g})\end{array}$ & $\begin{array}{c}\text { OSC/B.E.T. } \\
\left(\mu \mathrm{mol} \mathrm{O} / \mathrm{m}^{2}\right)\end{array}$ & $\begin{array}{c}\text { Calcd OSC } \\
\left(\mu \mathrm{mol} \mathrm{O} / \mathrm{m}^{2}\right)\end{array}$ \\
\hline Nanopolyhedra & 318 & 5.1 & 6.2 \\
Nanorods & 554 & 9.1 & 4.9 \\
Nanocubes & 353 & 10.6 & 5.7 \\
\hline
\end{tabular}

${ }^{a} \mathrm{CO}-\mathrm{OSC}$ measured at $400^{\circ} \mathrm{C}$. ${ }^{\mathrm{b}} \mathrm{Calculated}$ according to the

theoretical OSC of exposed surfaces. See ref. 26 for details. 
Figure 1
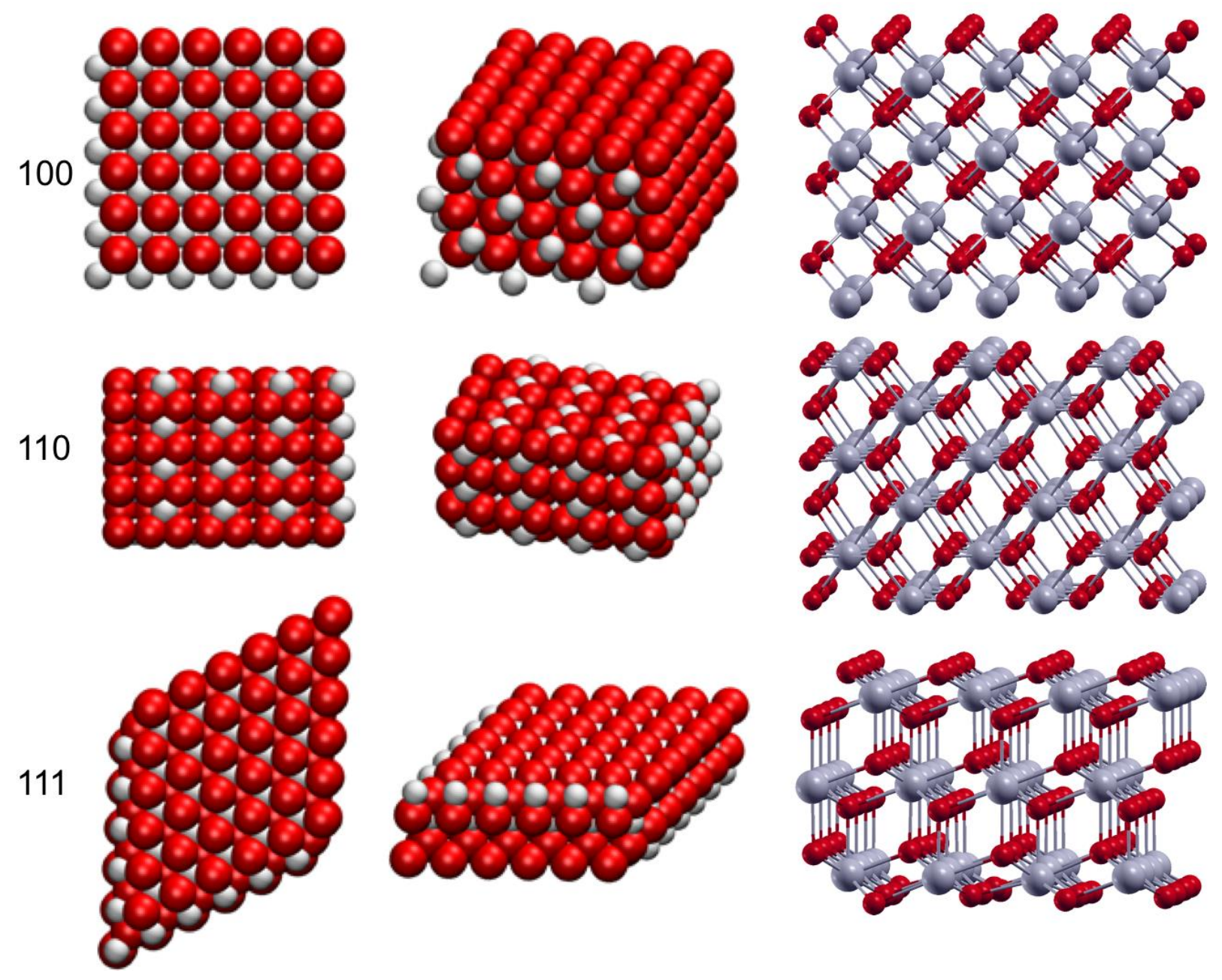

Figure 1. Top, side and perspective view of $\mathrm{CeO}_{2}(100),(110)$ and (111) surfaces. Gray and red spheres represent cerium and oxygen ions respectively. 
Figure 2

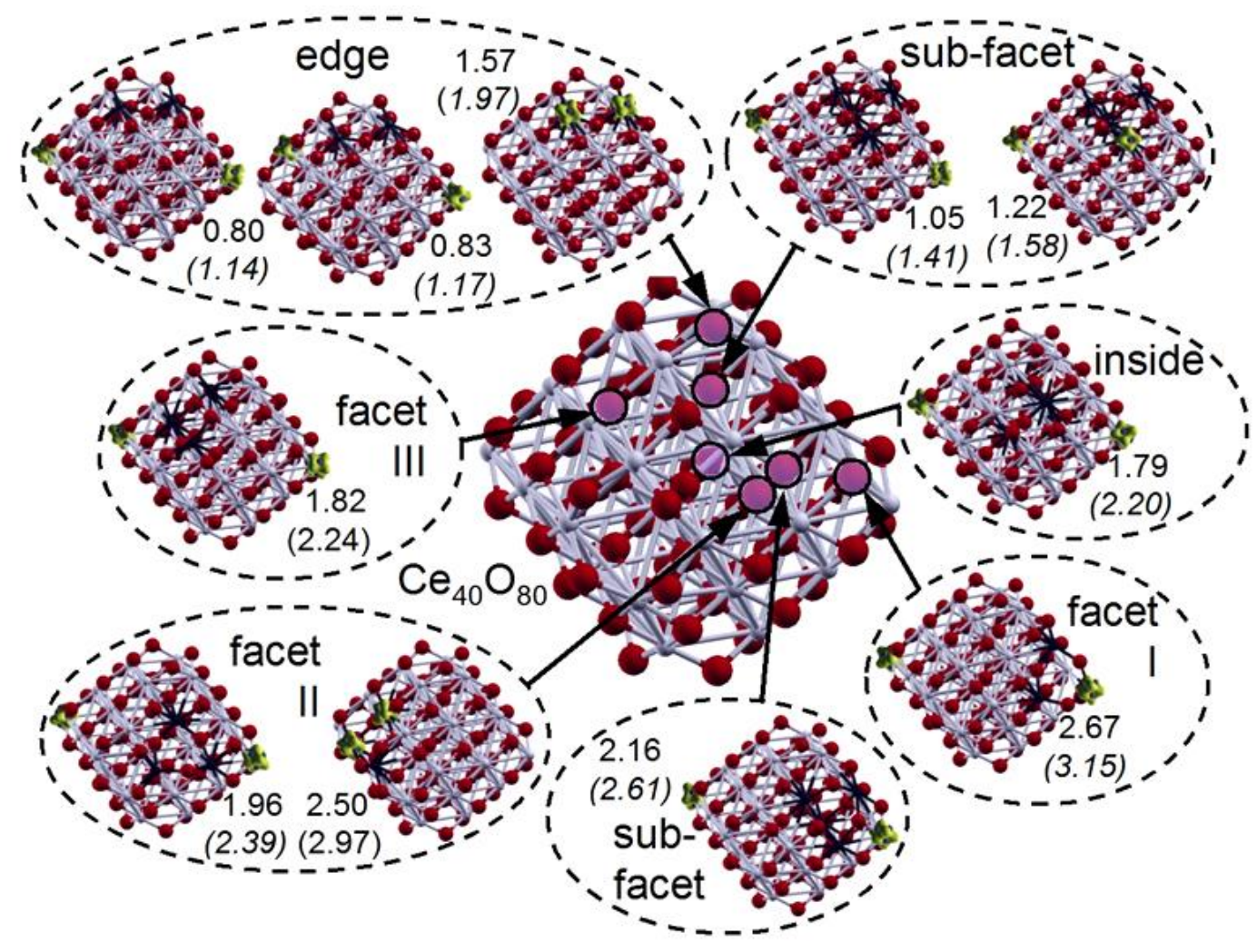

Figure 2. Representation of $\mathrm{Ce}_{40} \mathrm{O}_{80}$ and $\mathrm{Ce}_{40} \mathrm{O}_{79}$ with oxygen vacancy in distinct positions (edge, different facet position, subfacets, inside). Vacancy formation energies are indicated in $\mathrm{eV}$ and calculated at the PW91+4 level (normal font), and estimated at the HSE06 level (italic). Black circles = depleted O atoms; Red = O; Grey $=\mathrm{Ce}$; Black $=\mathrm{Ce}^{3+/ 4+}$ first neighbors to the $\mathrm{O}_{\text {vac; }}$ Green = spin-density on $\mathrm{Ce}^{3+}$. Reproduced from ref. 62 with permission from The Royal Society of Chemistry. 
Figure 3

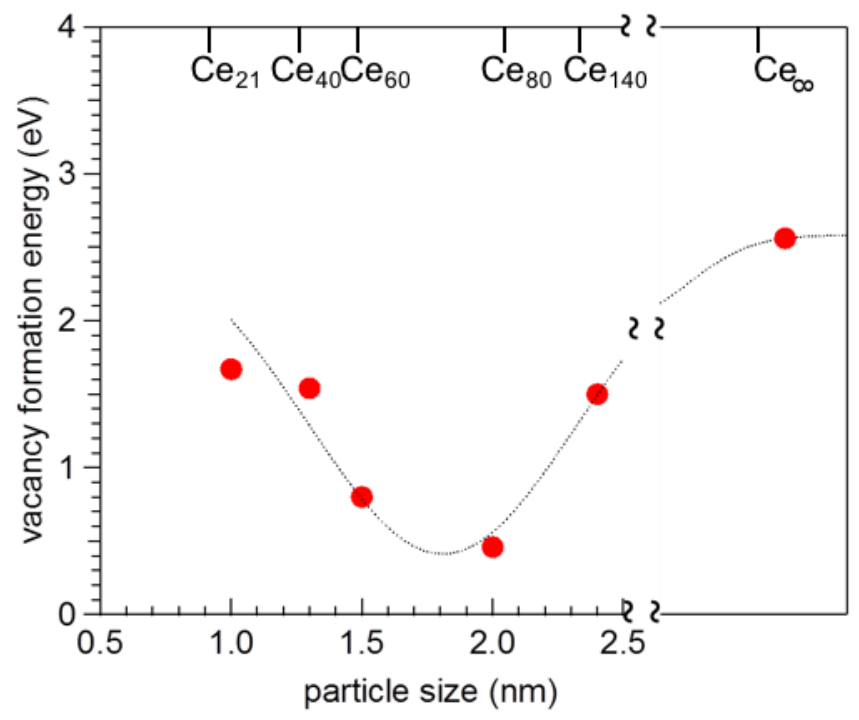

Figure 3. Size dependence of vacancy formation energy for different ceria nanoparticles. Data from ref. 63. 
Figure 4

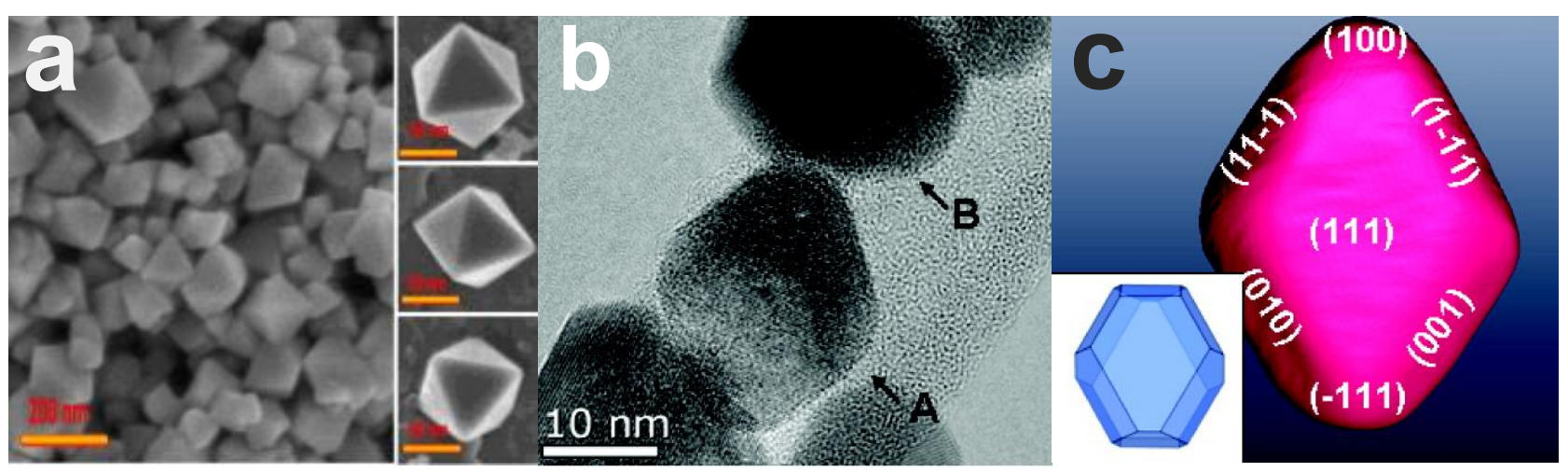

Figure 4. $\mathrm{CeO}_{2}$ crystals prepared by hydrothermal methods: (a) FE-SEM image of $\mathrm{CeO}_{2}$ nanooctahedrons and individual nano-octahedron seen from three different views. Adapted with permission from ref. 73. Copyright (2014) Elsevier. (b) Bright-field image of large $\mathrm{CeO}_{2}$ particles and (c) surface 3D rendering view of the structure of particle A. Adapted with permission from ref. 72. Copyright (2011) American Chemical Society. 
Figure 5

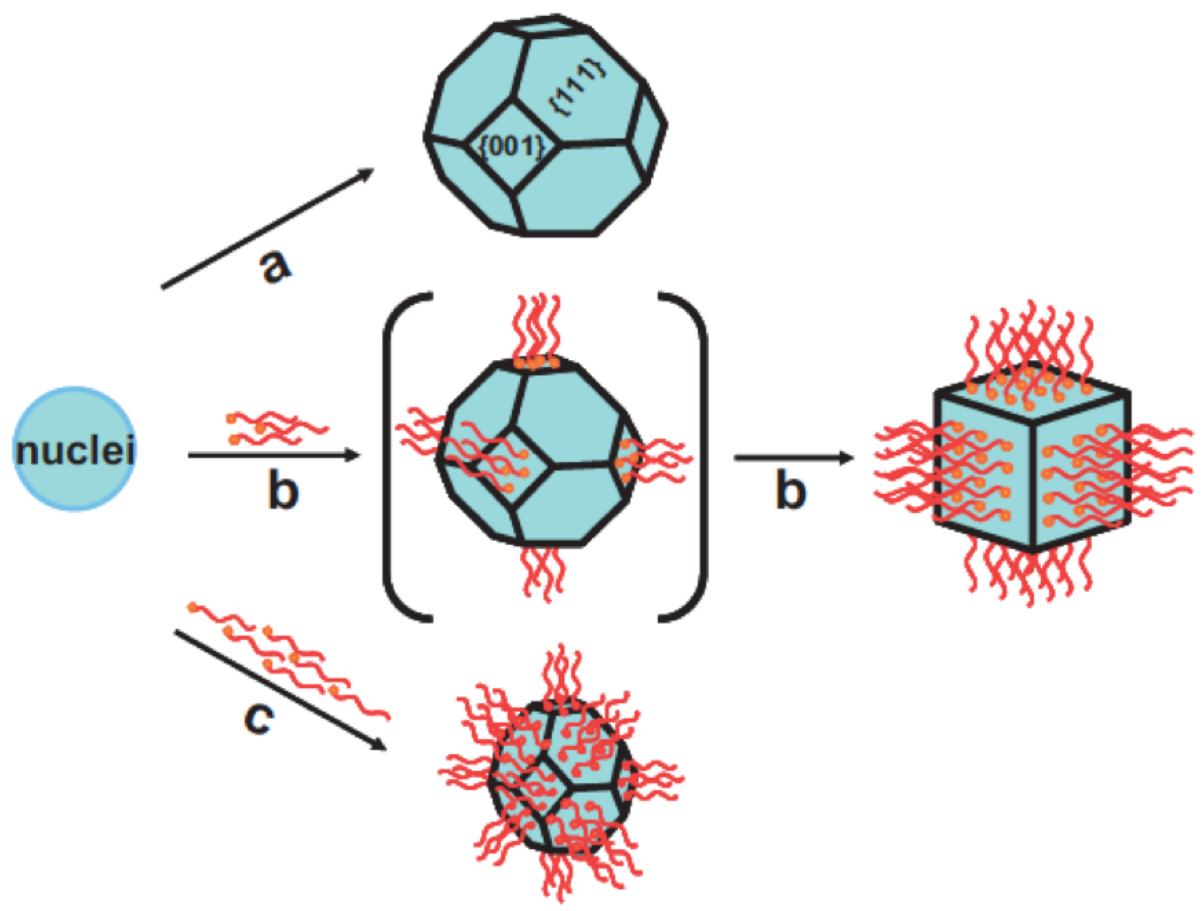

Figure 5. Control of nanocrystal shape through the use of surface capping agents. Interaction of dodecanoic acid with $\{100\}$ surfaces slows the growth in this direction leading to formation of nanocubes (path b). In excess of dodecanoic acid, growth in both directions is reduced with formation of small truncated octahedral particles (path c) compared to path a with no capping agent. Adapted from ref. 77. Copyright (2007), with permission from John Wiley and Sons. 
Figure 6
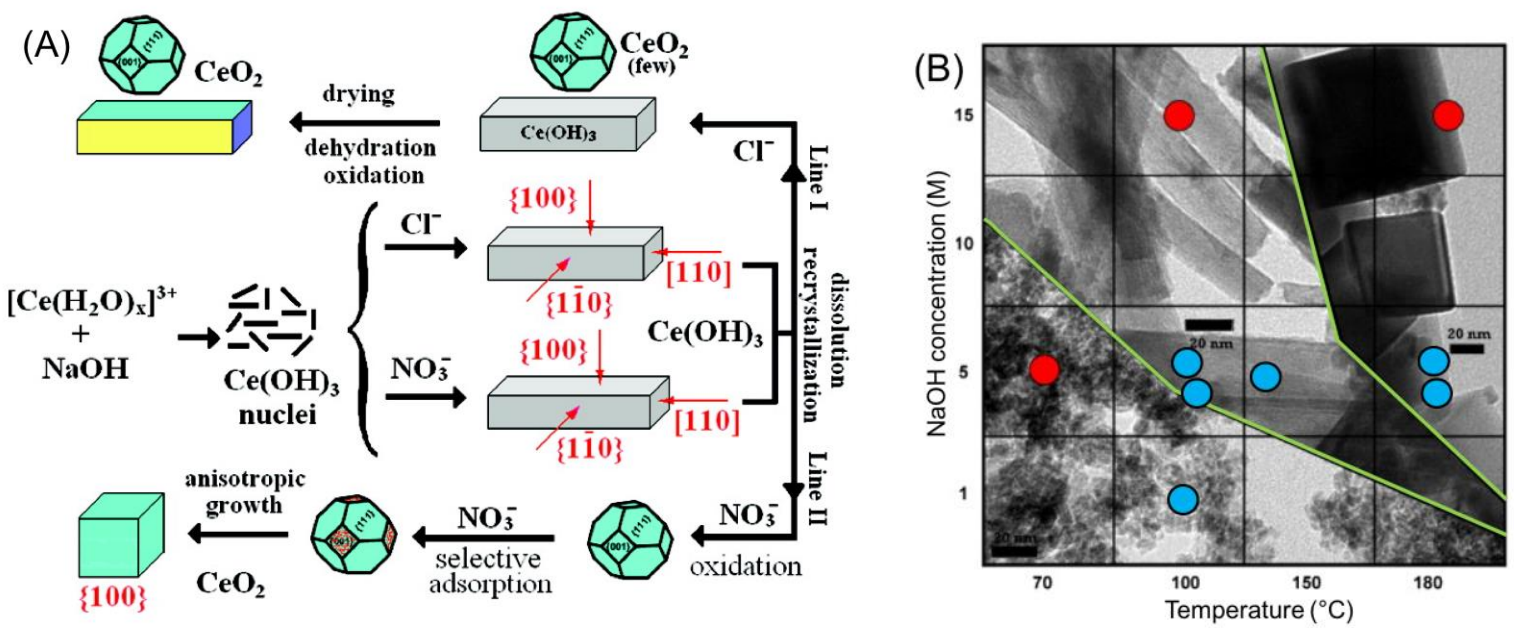

Figure 6. Left: schematic illustration for the conversion from nanorods to nanocubes; Adapted with permission from ref. 86. Copyright (2008) American Chemical Society. Right: morphological phase diagram of $\mathrm{CeO}_{2}$ after hydrothermal treatment. Red circles refer to the original points while blue circles are values taken from the literature; Adapted with permission from ref. 88. Copyright (2013) Elsevier. 
Figure 7
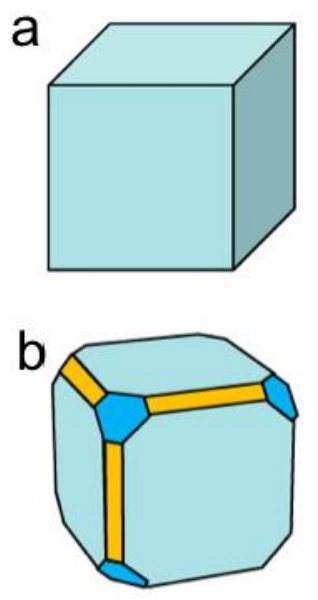
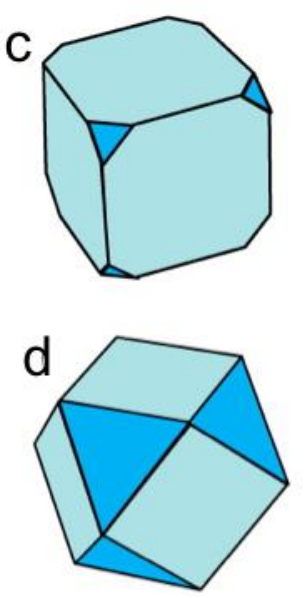

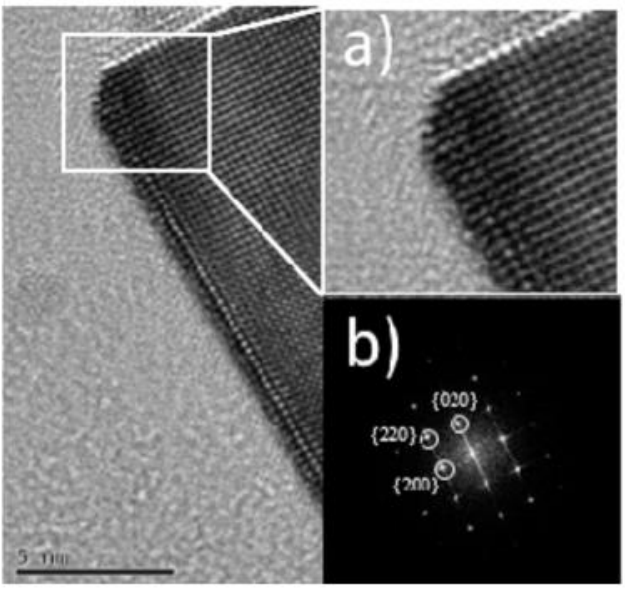

Figure 7. (Left) Various geometrical shapes of nanocubes giving a square symmetry in a classical TEM image: (a) cube, (b) cube with edges truncated, (c) cube with corners and edges truncated, and (d) cube-octahedron. (Right) Representative HRTEM image of a $\mathrm{CeO}_{2}$ nanocube. Inset: (a) magnified area in the vicinity of a corner allowing the observation of its geometry; (b) the corresponding Fourier transform. Adapted with permission from ref. 74. Copyright (2013) American Chemical Society. 
Figure 8

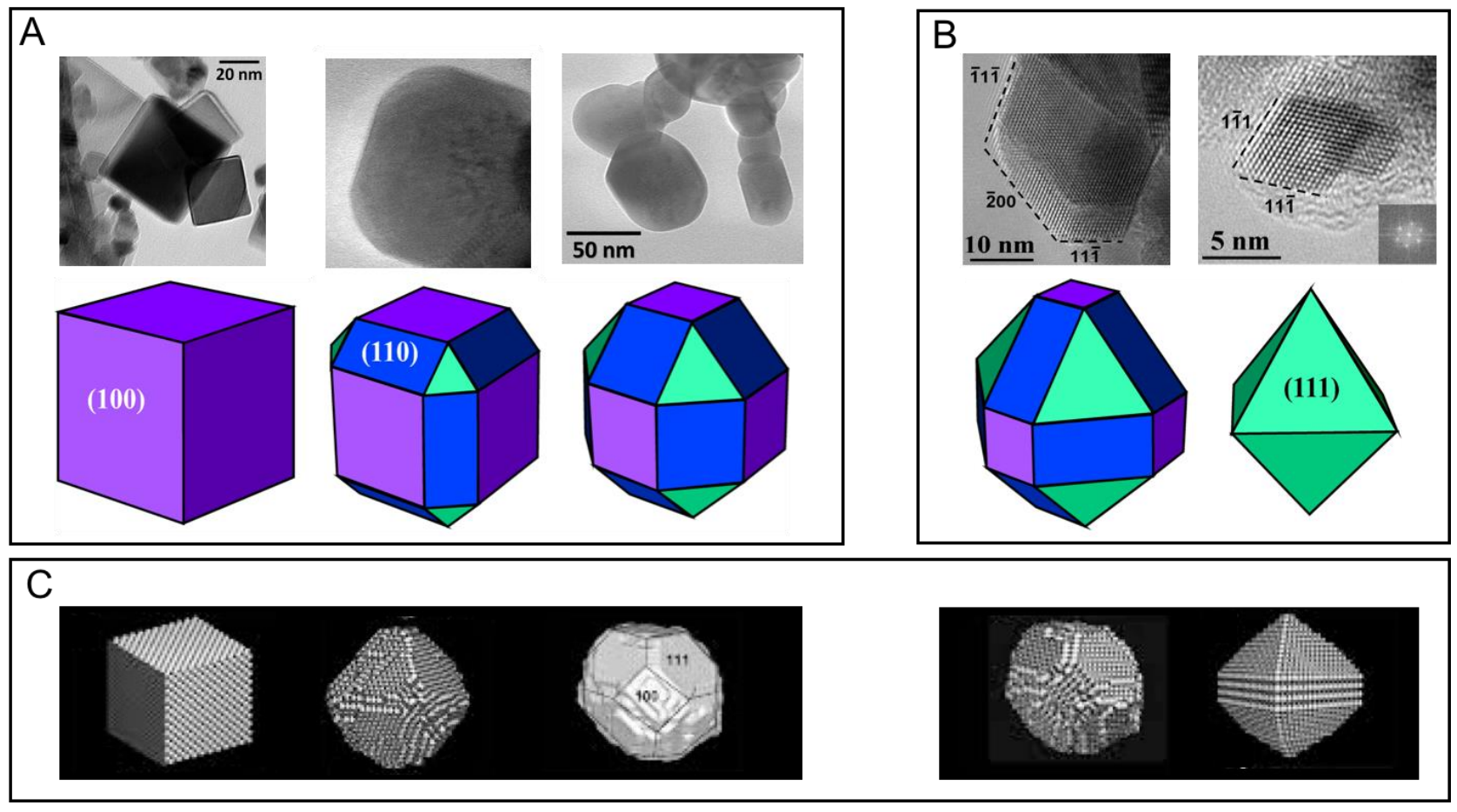

Figure 8. (A) HRTEM images showing the transition of cubic particles into edge- and cornertruncated cubes and truncated octahedra induced by thermal treatments along with a geometrical representation of the particle shapes. (B) HRTEM images showing the transformation of octahedral nanoparticles to truncated octahedral in polycrystalline ceria samples induced by thermal treatments with a geometrical representation of the particle shapes. Adapted with permission from ref. 96 Copyright 2014 American Chemical Society and ref. 36 Copyright 2005 Elsevier. (C) Representation of ceria nanoparticles generated using an amorphisation and recrystallization mechanism. Adapted with permission from ref. 100. Copyright 2004 The Royal Society of Chemistry 


\section{Figure 9}

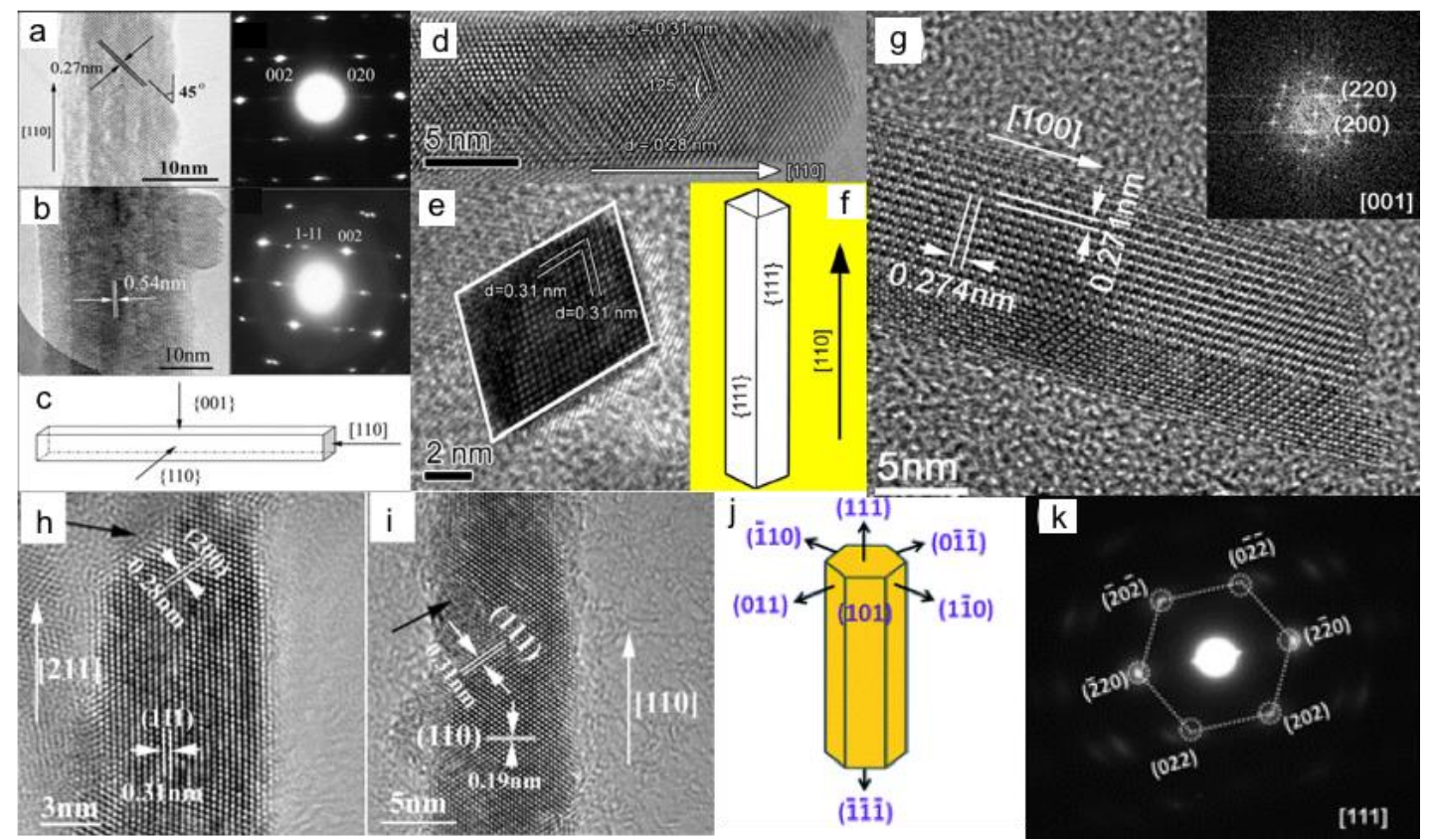

Figure 9. (a) magnified HRTEM view of a $\mathrm{CeO}_{2}$ nanorod along [001] and (b) along [110] with the corresponding SAED patterns; (c) schematic model of the nanorod growing along [110]. Adapted from ref. 35. Copyright 2005 Elsevier. (d) HRTEM image of nanorod growing along [110] enclosed by $\{111\}$ planes with the (e) cross section view and (f) schematic model. Adapted from ref. 108. Copyright 2012 American Chemical Society. (g) HRTEM image of an individual nanorod growing along [110] and its FFT pattern; Adapted from ref. 81. Copyright (C) 2008 American Chemical Society. (h, i) HRTEM images of ceria nanorods growing along [211] and [110]; Adapted from ref. 28. Copyright 2007 American Chemical Society. (j) schematic diagram of nanorod growing along [111] with (k) its SAED pattern; Adapted from ref. 102. Copyright 2011 Royal Society of Chemistry. 
Figure 10
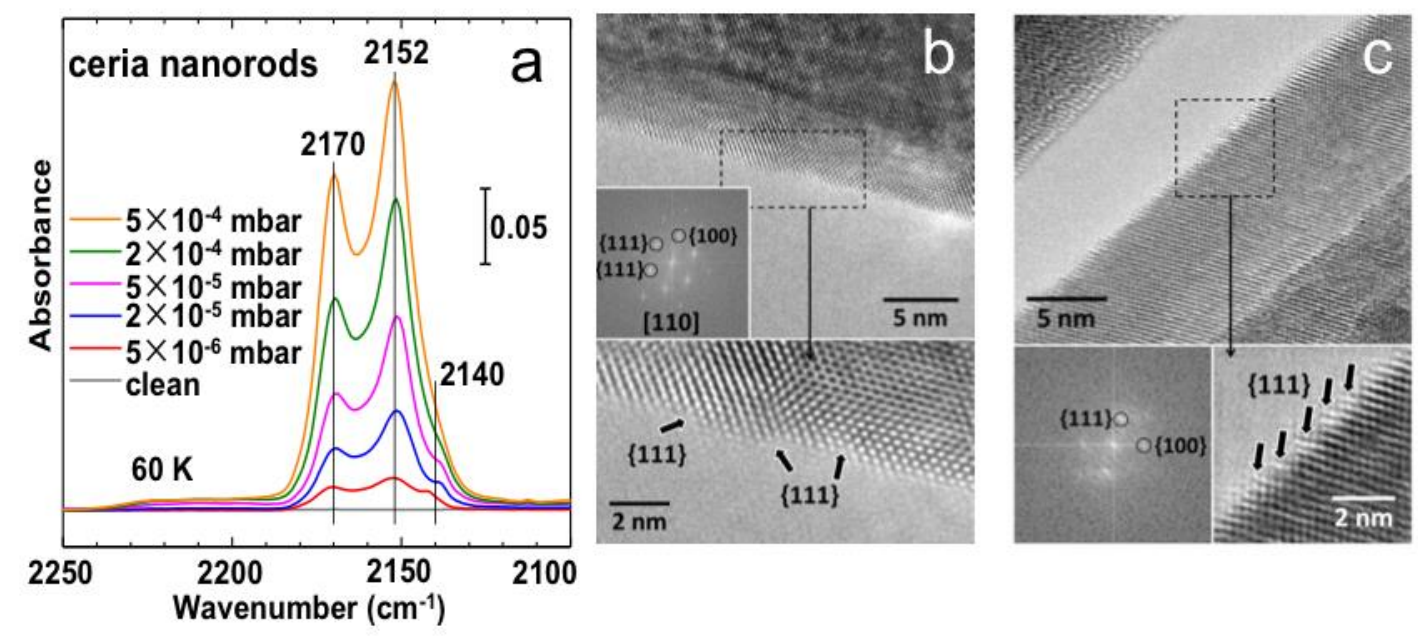

Figure 10. (a) CO adsorption on ceria nanorods with bands at 2170 and $2152 \mathrm{~cm}^{-1}$ due to adsorption on $\{110\}$ and $\{111\}$ surfaces respectively $(b, c)$. High-magnification HRTEM images of $\mathrm{CeO}_{2}$ nanorods showing the $\{111\}$ facets formed on the (110) plane. Adapted with permission from ref. 110. Copyright Wiley-VCH (2017). 
Figure 11
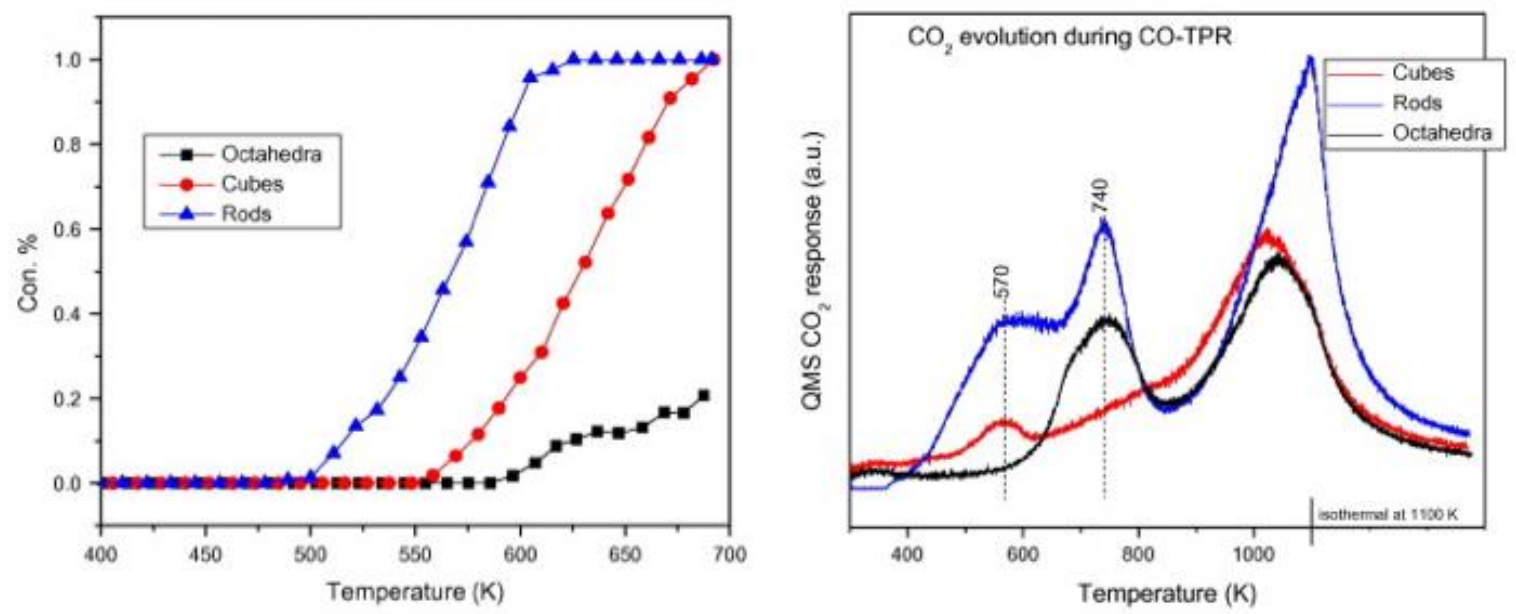

Figure 11. (left) Light-off curves for $\mathrm{CO}$ oxidation over ceria rods, cubes, and octahedra. Reaction conditions: catalyst $\sim 50 \mathrm{mg}$, reaction feed: $10 \mathrm{~mL} / \mathrm{min} 2 \% \mathrm{CO} / \mathrm{Ar} / \mathrm{He}+30 \mathrm{~mL} / \mathrm{min} 5 \% \mathrm{O}_{2} / \mathrm{He}$. (right) $\mathrm{CO}_{2}$ evolution during CO-TPR. Adapted from ref. 126. Copyright (2012), with permission from Elsevier 
Figure 12

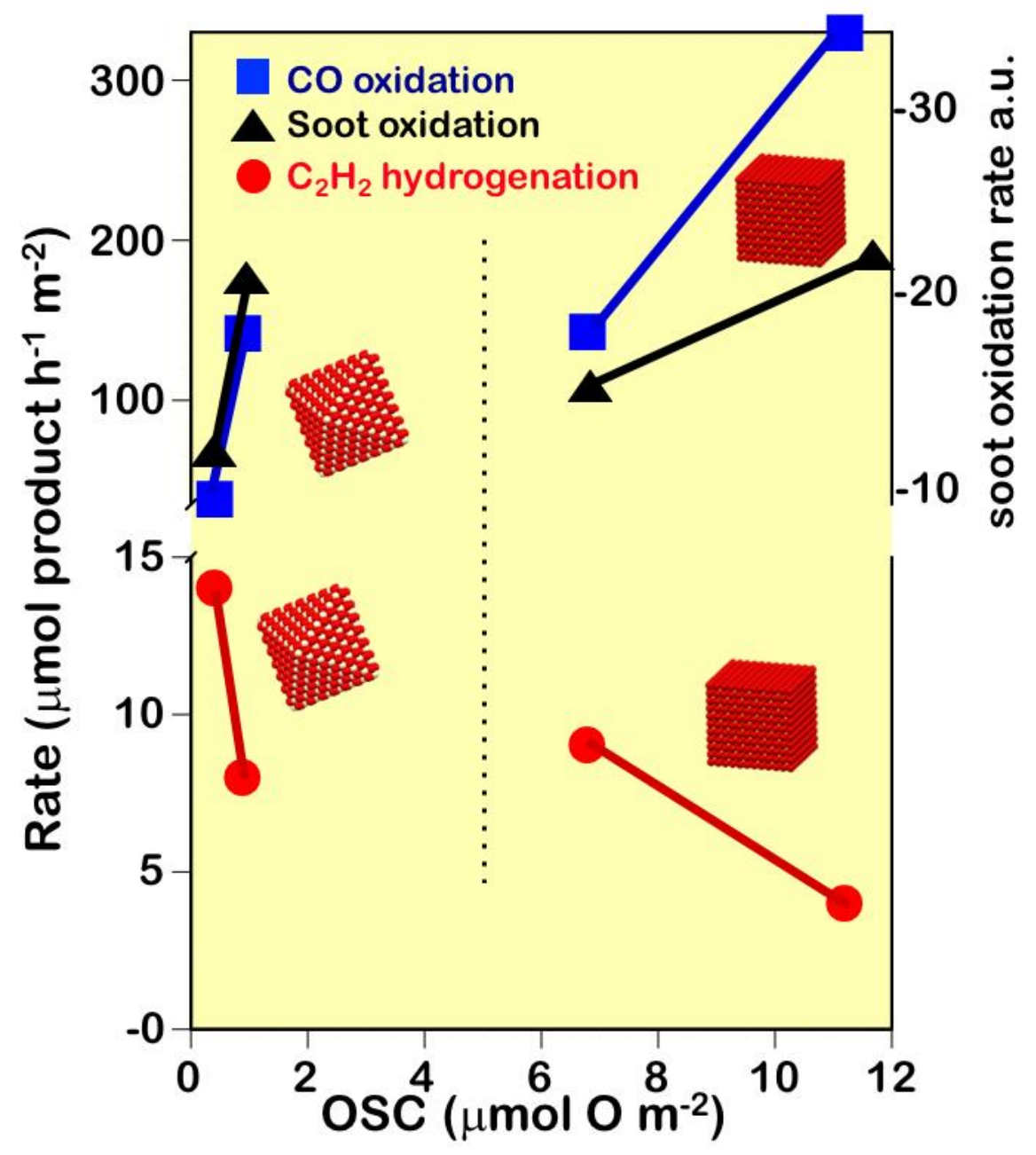

Figure 12. Rate of $\mathrm{CO}$ and $\mathrm{C}$-soot oxidation and $\mathrm{C}_{2} \mathrm{H}_{2}$ hydrogenation against OSC as measured in polyhedral and cubic shaped nanoparticles. Adapted from ref. 147. Copyright (2014), with permission from John Wiley and Sons. 
Figure 13
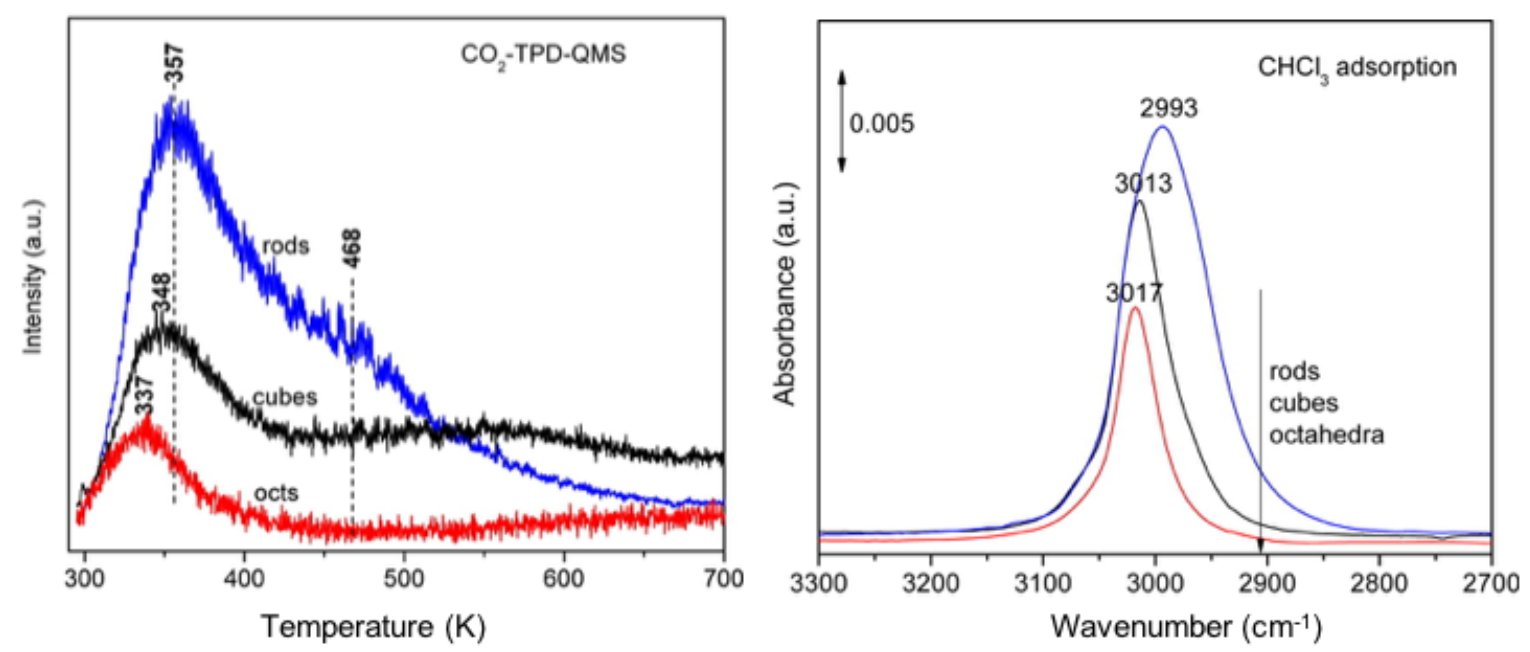

Figure 13. Left: $\mathrm{CO}_{2}$-TPD profiles obtained over ceria nanoshapes (surface area normalized mass 44 signal); right: IR spectra from $\mathrm{CHCl}_{3}$ adsorbed at room temperature on ceria nanoshapes calcined at $673 \mathrm{~K}$. Adapted with permission from ref. 152 Copyright 2015, American Chemical Society. 
Figure 14

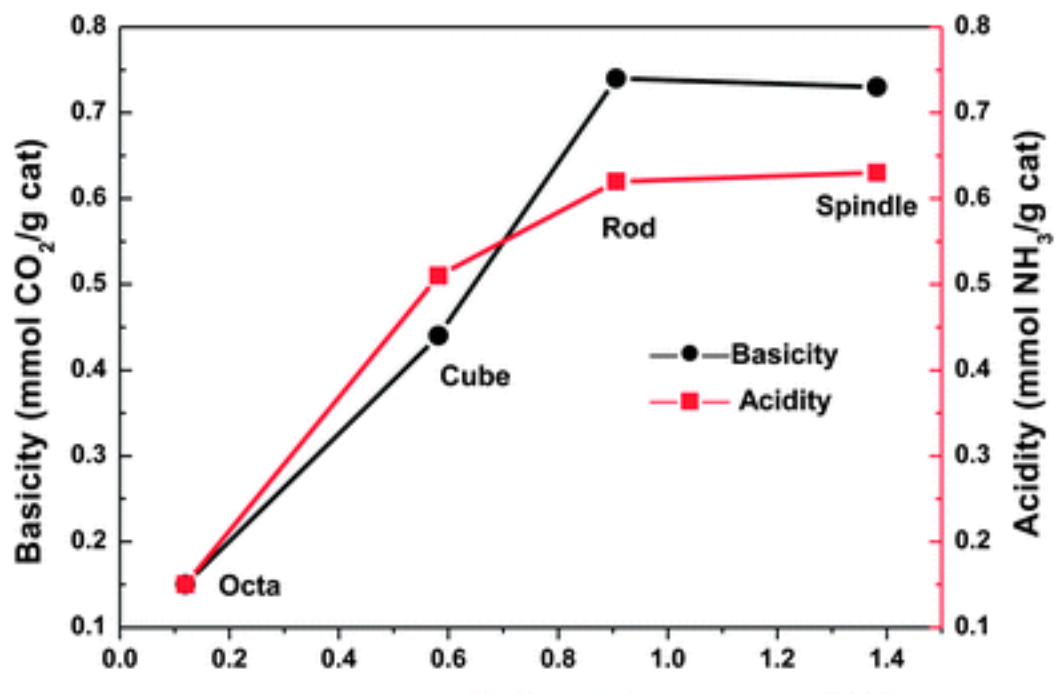

Catalytic performance of $\mathrm{CeO}_{2}$ catalysts (mmol DMC/g cat)

Figure 14. Correlation between acidity/basicity and catalytic performance of $\mathrm{CeO}_{2}$ catalysts with different morphologies in dimethyl carbonate formation from $\mathrm{CO}_{2}$ and methanol. Reproduced from ref. 109 with permission from The Royal Society of Chemistry. 
Figure 15
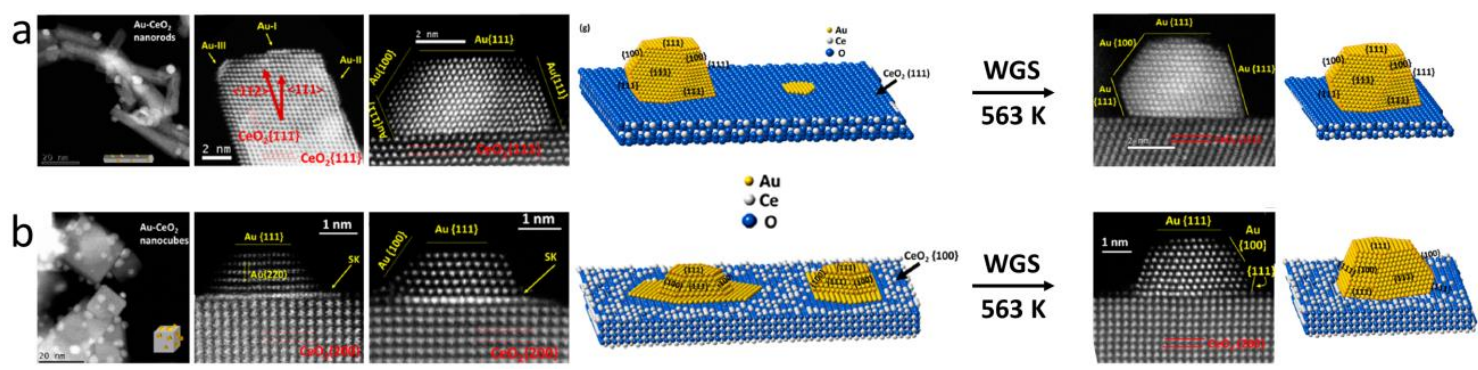

Figure 15. HAADF-STEM images recorded over Au nanoparticles supported on $\mathrm{CeO}_{2}$ nanorods (a) and nanocubes (b) before and after WGS. The $\mathrm{Au}-\mathrm{CeO}_{2}$ interface in the ceria nanocubes shows a Stranski-Krastanov-type (SK) growth mode as a balance between strong metal-support interaction and strong metal-metal interaction, which disappears after WGS and the catalyst deactivates. In contrast, Au nanoparticles on ceria nanorods are unchanged after WGS and perform better. Adapted with permission from ref. 101. Copyright 2015 American Chemical Society. 
Figure 16

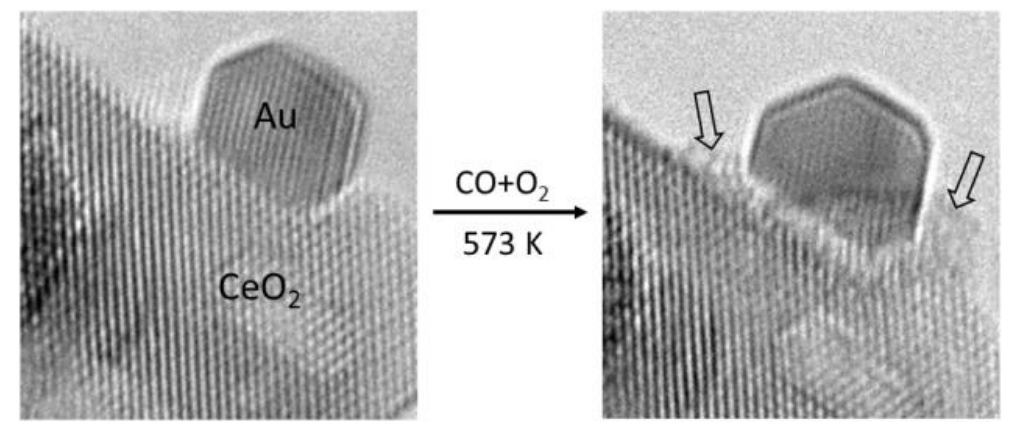

Figure 16. ETEM images recorded over $\mathrm{Au} / \mathrm{CeO}_{2}$-nanorods. Under $\mathrm{CO}$ oxidation conditions a restructuration of the $\mathrm{Au}-\mathrm{CeO}_{2}$ interface occurred, resulting in disordered ceria layers adjacent to the Au nanoparticles. Adapted with permission from ref. 108. Copyright 2012 American Chemical Society. 
Figure 17
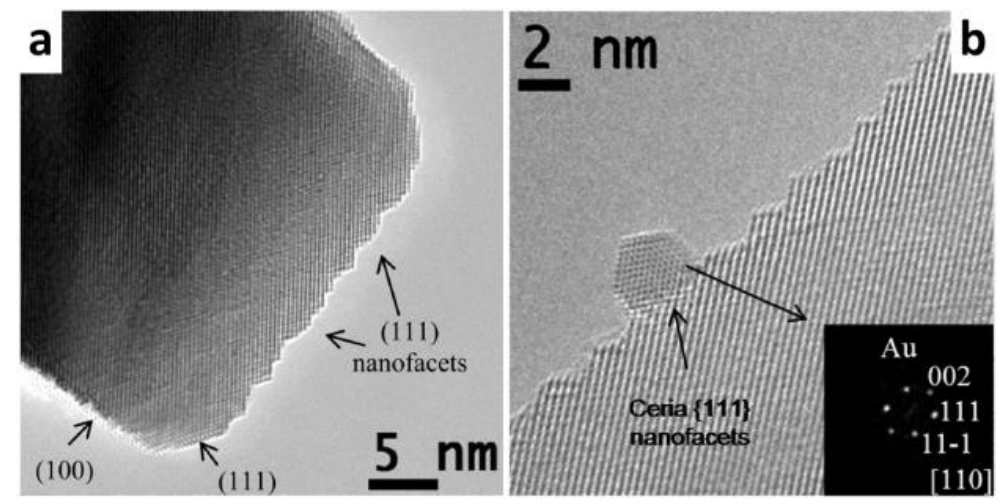

Figure 17. HRTEM images recorded over reconstructed $\mathrm{CeO}_{2}$ nanocubes with $\{111\}$ nanofacets (a) and the corresponding $\mathrm{Au} / \mathrm{CeO}_{2}$ catalyst (b). Au nanoparticles are preferentially located in the valley locations of the zigzagged $\{111\}$ nanofacets of the ceria support. Adapted with permission from ref. 97. Copyright 2015 American Chemical Society. 


\section{Figure 18}
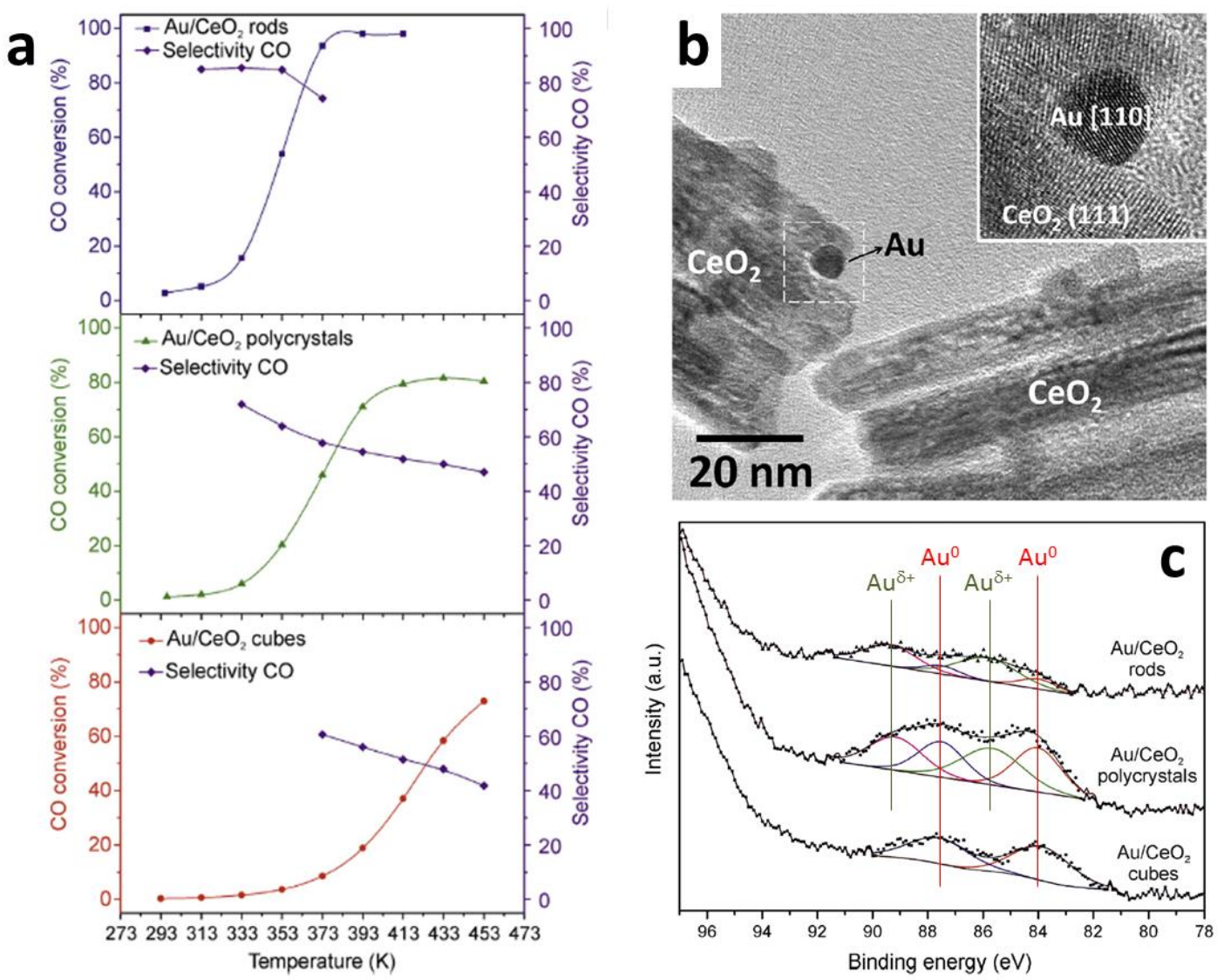

Figure 18. A. COPrOx catalytic performance of preformed Au nanoparticles dispersed over ceria nanopolyhedra, nanocubes and nanorods (CO: $\mathrm{O}_{2}: \mathrm{N}_{2}: \mathrm{H}_{2}=1: 1: 23: 25$ molar); B. HRTEM image of $\mathrm{Au} / \mathrm{CeO}_{2}$ nanorods; C. Au $4 \mathrm{f}$ photoemission spectra. Adapted with permission from ref. 181 Copyright 2016 Elsevier. 
Figure 19

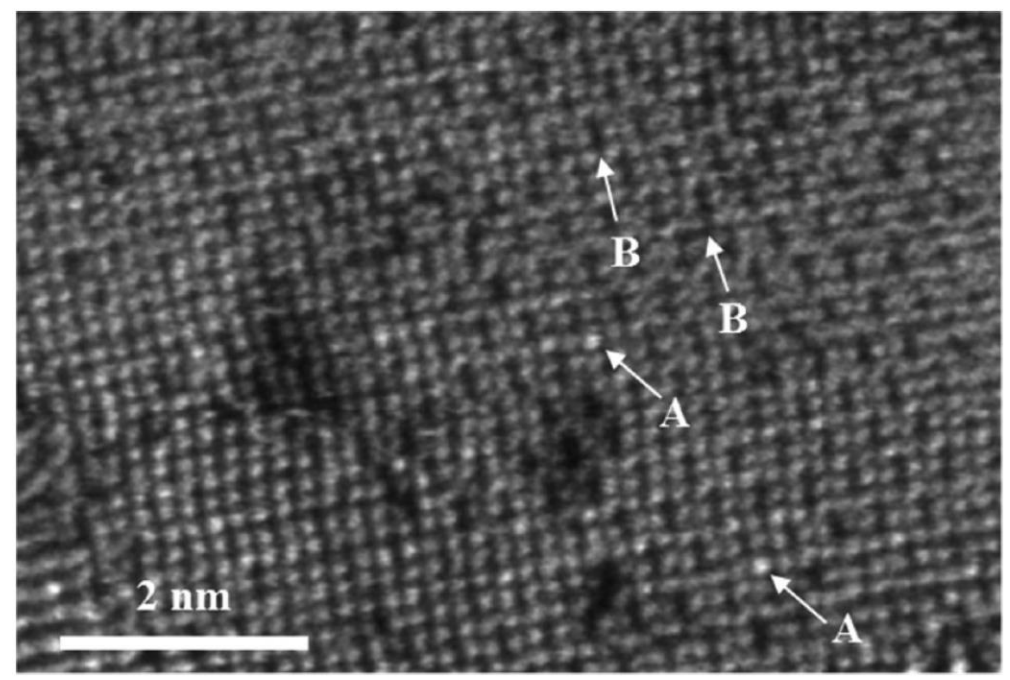

Figure 19. HAADF-STEM image recorded over $\mathrm{Au} / \mathrm{CeO}_{2}$ containing $\mathrm{Au}$ single atoms (bright atoms indicated by A) and many clusters of Ce vacancies (indicated by B). The oxygen atoms are not visible under this imaging mode. Reproduced with permission from ref. 184. Copyright 2017 American Chemical Society. 


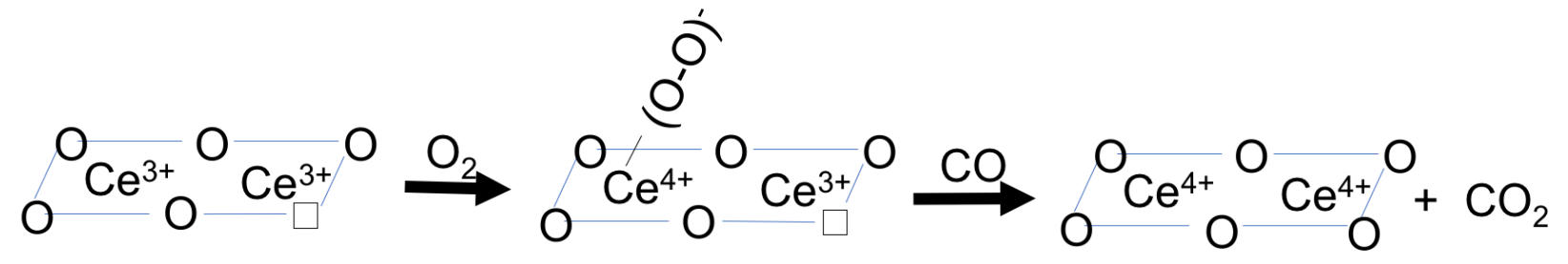

a) ${ }_{\mathrm{Ce}}^{\mathrm{O}} \mathrm{O} \underset{\mathrm{Ce}}{\mathrm{Ce}^{4+}} \stackrel{\mathrm{CO}}{\longrightarrow}{ }_{\mathrm{Ce}^{3+}}^{\mathrm{O}} \mathrm{O}_{\mathrm{Ce}^{3+}}^{\mathrm{O}}+\mathrm{CO}_{2}$

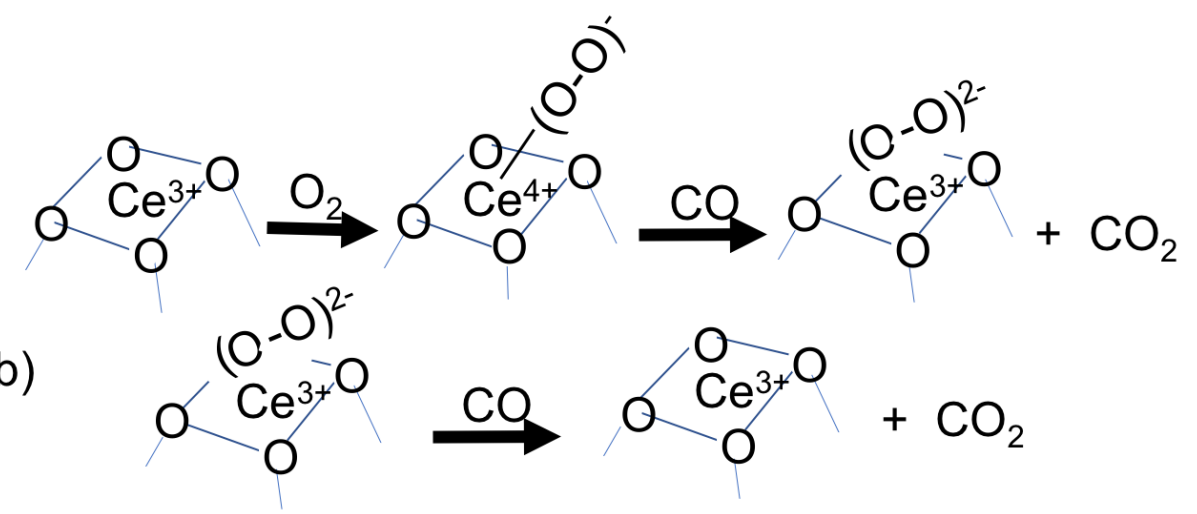

Scheme 1. (a) Reduction-oxidation cycle operated by $\mathrm{CO} / \mathrm{O}_{2}$ over ceria surfaces in the presence of superoxide and $\mathrm{Ce}^{3+}$ with associated vacancy. $\mathrm{CO}$ reacts with superoxide formed by interaction at a top site of $\mathrm{Ce}^{3+}$ apart from an oxygen vacancy ${ }^{123}$. (b) Sketch of a conceivable reduction oxidation cycle operated by $\mathrm{CO} / \mathrm{O}_{2}$ over small size ceria NPs in the presence of $\mathrm{Ce}^{3+}$ not associated with a vacancy and located in defect position. 
Table of Content - graphical abstract

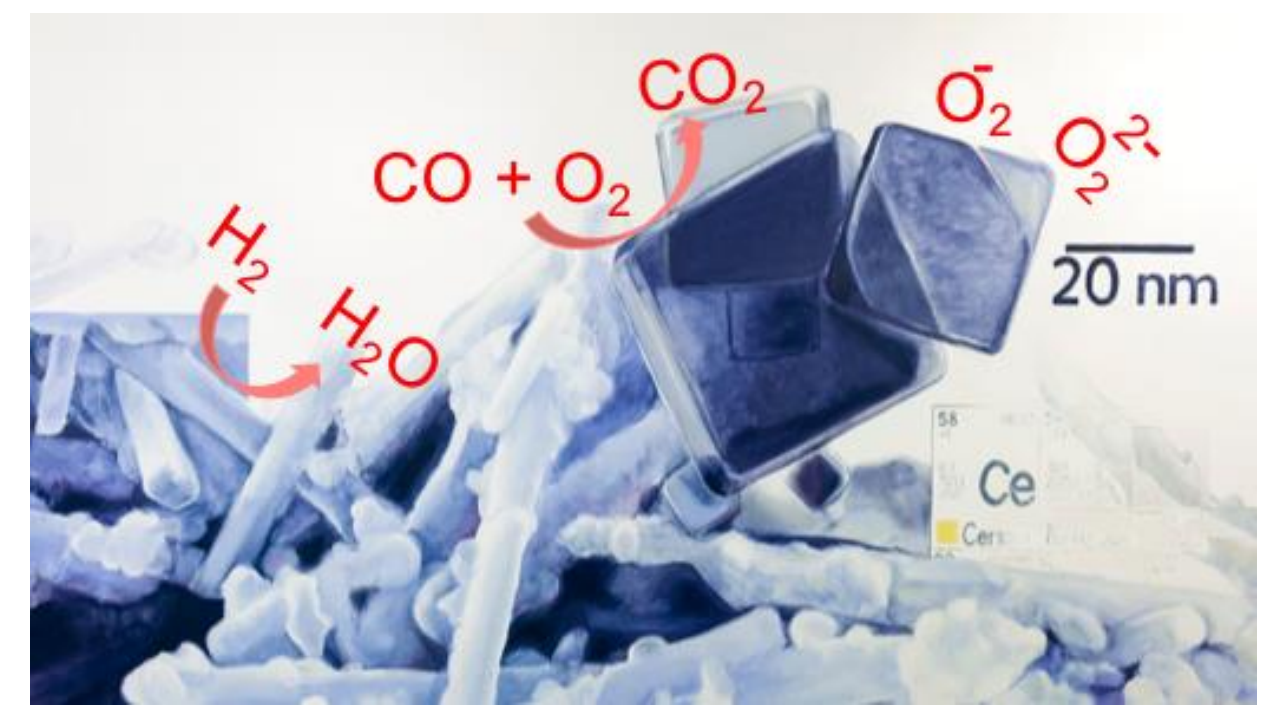

